\title{
Development of Techniques for Assessment of Population Characteristics of the Federally Endangered Diamond Darter
}

Austin A. Rizzo

Follow this and additional works at: https://researchrepository.wvu.edu/etd

\section{Recommended Citation}

Rizzo, Austin A., "Development of Techniques for Assessment of Population Characteristics of the Federally Endangered Diamond Darter" (2017). Graduate Theses, Dissertations, and Problem Reports. 6511.

https://researchrepository.wvu.edu/etd/6511

This Dissertation is protected by copyright and/or related rights. It has been brought to you by the The Research Repository @ WVU with permission from the rights-holder(s). You are free to use this Dissertation in any way that is permitted by the copyright and related rights legislation that applies to your use. For other uses you must obtain permission from the rights-holder(s) directly, unless additional rights are indicated by a Creative Commons license in the record and/ or on the work itself. This Dissertation has been accepted for inclusion in WVU Graduate Theses, Dissertations, and Problem Reports collection by an authorized administrator of The Research Repository @ WVU.

For more information, please contact researchrepository@mail.wvu.edu. 


\title{
DEVELOPMENT OF TECHNIQUES FOR ASSESSMENT OF POPULATION CHARACTERISTICS OF THE FEDERALLY ENDANGERED DIAMOND DARTER
}

\author{
Austin A. Rizzo \\ Dissertation submitted to the \\ Davis College of Agriculture, Natural Resources, and Design \\ at West Virginia University \\ in partial fulfillment of the requirements for the degree of
}

Doctor of Philosophy

in

Forest Resource Science
Stuart A. Welsh, Ph.D., Chair
Patricia M. Mazik, Ph.D. Mike Strager, Ph.D. Jered M. Studinski, Ph.D. Richard L. Raesly, Ph.D.

School of Natural Resources

Wildlife and Fisheries Resources Program

\section{Morgantown, West Virginia 2017}

Keywords: Fish, Flood, Detectability, Disturbance, $N$-mixture Model, Rare Species, Simulations 


\title{
ABSTRACT \\ Development of techniques for assessment of population characteristics of the federally endangered Diamond Darter
}

\begin{abstract}
Austin A. Rizzo
Population monitoring is an essential component of endangered species recovery programs. One species for which monitoring is needed is the federally endangered Diamond Darter Crystallaria cincotta. This species was placed on the Endangered Species List in 2013 because of its small range and population size, and because of continued anthropogenic threats to the species' habitat. The Diamond Darter is believed to occur only within the lower $50 \mathrm{rkm}$ of the Elk River in West Virginia. Museum specimens indicate the Diamond Darter was once distributed throughout the Ohio River Basin, but it is now likely extirpated from the Muskingum River, the Ohio River, the Green River, and the Cumberland River drainages. Because of the Diamond Darter's small size, cryptic coloration, nocturnal behavior, and seemingly patchy distribution, along with limitations associated with current sampling methods, the species may appear to be rarer than it actually is. This may have also contributed to its late discovery as a species in 2008.

As a result of several of the above-mentioned factors, the Diamond Darter is a much understudied fish with very little known about life history, population size, or current distribution. One problem with monitoring populations of rare and elusive species is detection. Failure to account for detection probability can be a major source of bias in presence-absence and count survey data, potentially resulting in false determination of species absence and underestimation of abundance, respectively. Additionally, if these variables are not accurately estimated, their relationship to associated habitat and environmental variables may also be inaccurate. Ultimately, not accounting for detection probability may lead to misinformed management decisions, which can prove costly for an endangered species. For this study, I sought to develop techniques that would allow for the assessment of population characteristics for this rare, elusive species.

In my first chapter, I evaluated the precision and accuracy of photogrammetric length measurements relative to direct board measurements of Greenside Darters Etheostoma blennioides and Variegate Darters Etheostoma variatum. Agreement between board and photogrammetric measurements were high for these species, supporting photogrammetry as a useful method for obtaining length measurements of benthic stream fishes. Consequently, I applied photogrammetry in a field study of the Diamond Darter and assessed length frequency of 199 individuals throughout the sampling season. Based on these data I was able to identify a single cohort using glide habitat and estimate growth rate throughout the summer.

My second chapter focused on determining if there were any seasonal and diel patterns in Diamond Darter detectability during population surveys. In addition to temporal factors, I also assessed five sampling covariates that might influence individual detection. $N$-mixture models were used to estimate site abundances and relationships between covariates and individual detectability. The best supported model included water temperature as a quadratic function influencing individual detectability, with temperatures around $22 \mathrm{C}$ resulting in the highest detection probability. Detection probability when surveying at the optimal temperature was approximately $6 \%$ and $7.5 \%$ greater than when surveying at $16 \mathrm{C}$ and $29 \mathrm{C}$, respectively. Two
\end{abstract}


variables, time of night and day of year, were not strong predictors of Diamond Darter detectability. The results of this study will allow researchers and agencies to maximize detection probability when surveying populations, resulting in greater monitoring efficiency and likely more precise abundance estimates.

In my third chapter, I assessed the impacts on an extreme flood event on Diamond Darter populations. To accomplish this, relative abundances for one cohort of this species were estimated using pre-flood and post-flood surveys at 15 sites. Our results indicate the short-term response of Diamond Darter relative abundances to this extreme event were negligible, indicating individuals are able to withstand high velocities and resist displacement or mortality. In addition, site-level abundances were estimated at three sentinel sites during 2015 and 2016 using a multinomial $\mathrm{N}$-mixture model that accounted for variation in detectability resulting from water temperature. Mean estimated abundance varied among the three sites and between the two years. Our results suggest there is substantial variation in year-class strength between the two cohorts we sampled. Using detection probabilities generated from our highest supported model, we conducted simulation modeling to determine the number of replicate surveys needed to confidently estimate abundances at a site. Mean abundance estimates were similar with $\geq 7$ replications. It is recommended that survey efforts at established sentinel sites be continued on an annual basis in order to help determine factors influencing year-class strength. 


\section{TABLE OF CONTENTS}

ACKNOWLEDGEMENTS

CHAPTER 1: A paired-laser photogrammetric method for in situ length measurement of benthic

fishes

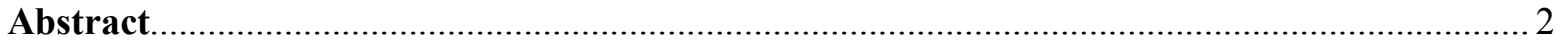

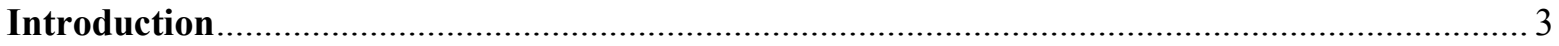

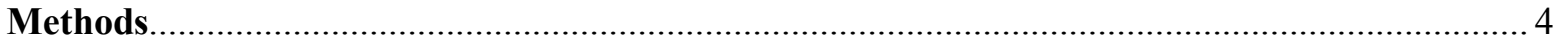

Measurements of Variegate and Greenside Darters ................................................................ 4

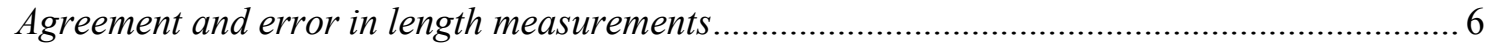

Measurement and assessment of Diamond Darter size structure ............................................. 6

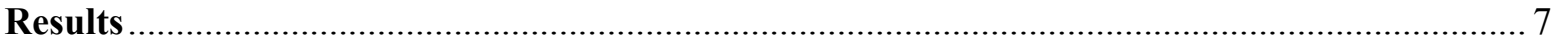

Temporal assessment of size structure for Diamond Darters .................................................... 8

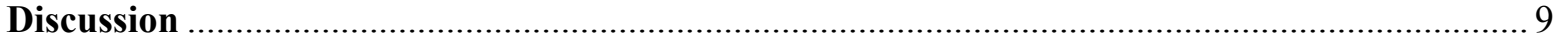

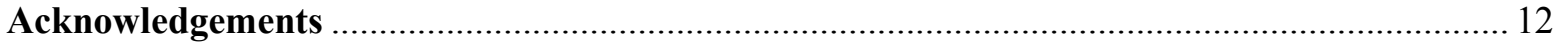

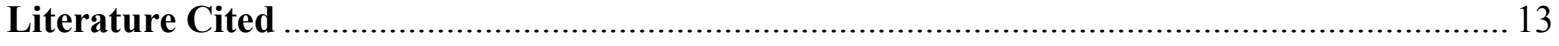

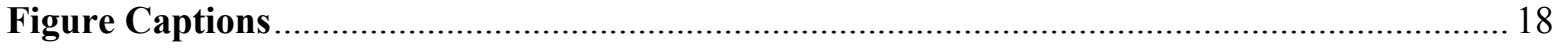

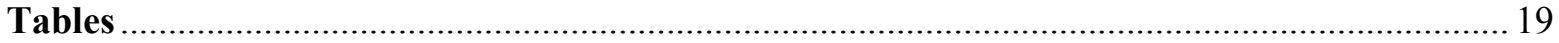

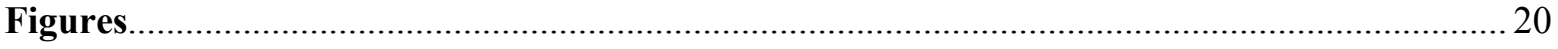

CHAPTER 2: Factors influencing detection of the federally endangered Diamond Darter

Crystallaria cincotta: implications for long-term monitoring strategies ..................................... 26

Abstract 
CHAPTER 3: Effects of an extreme flood event on federally endangered Diamond Darter populations: suggestions for survey and analysis design for future monitoring efforts

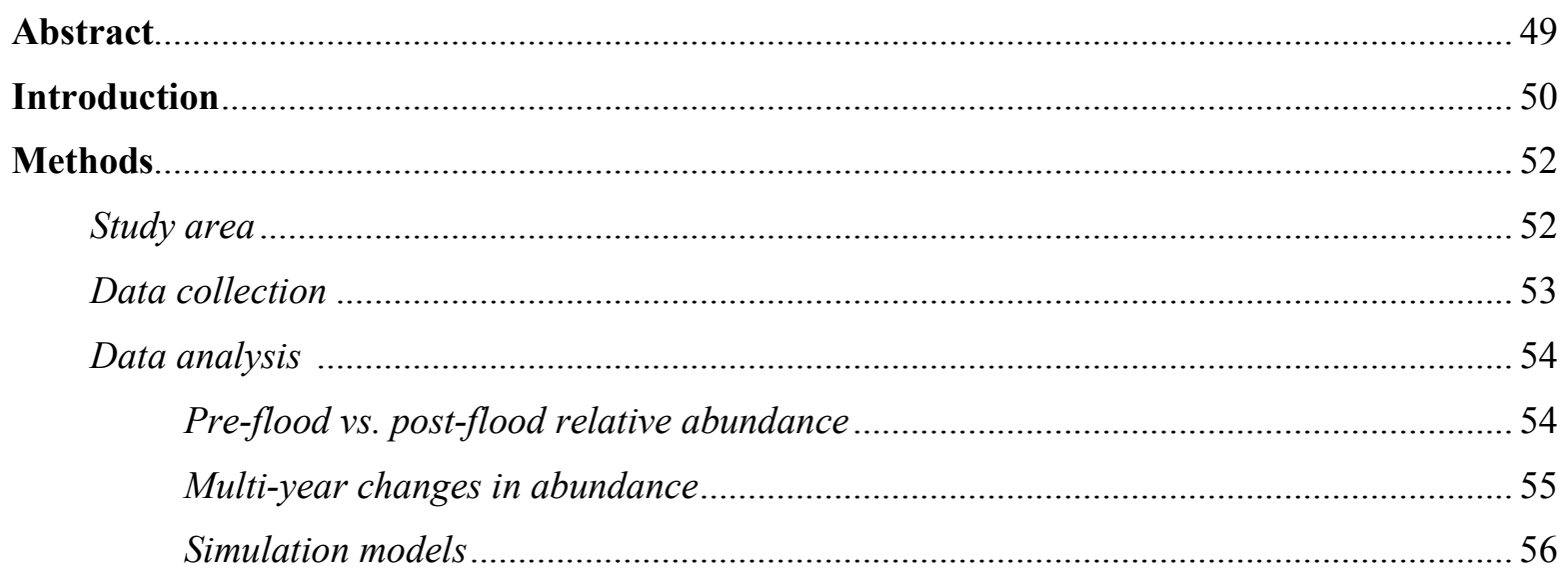

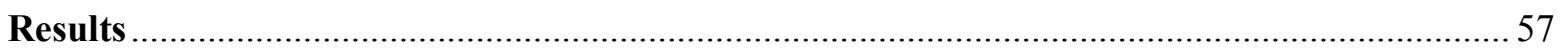

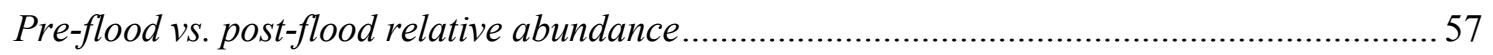

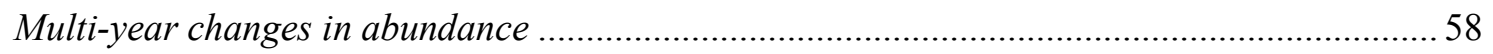

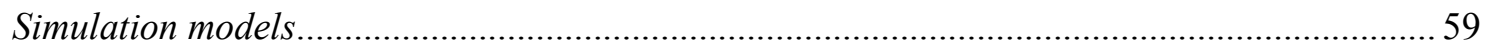

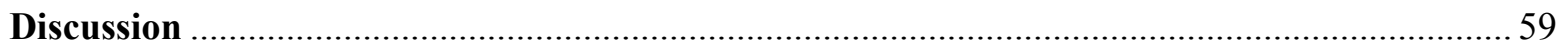

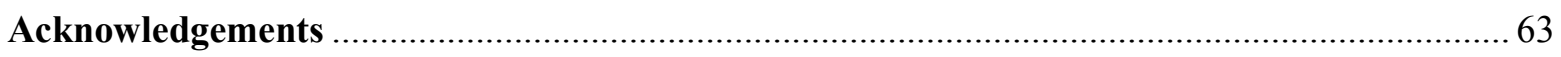

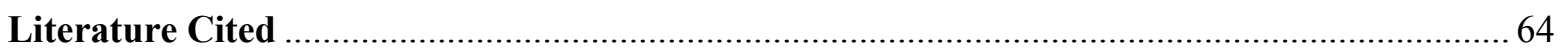

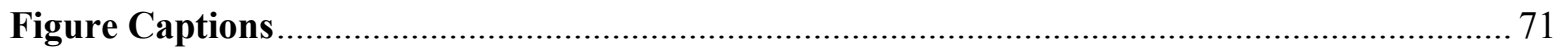

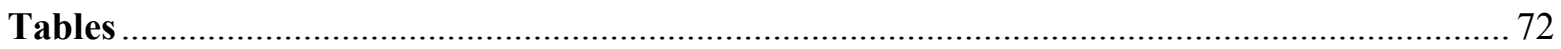

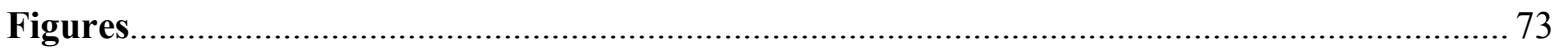




\section{ACKNOWLEDGEMENTS}

There are many people who I owe thanks to for helping me while at West Virginia University. First and foremost, I would like to express my great appreciation to my advisor, Dr. Stuart Welsh, for his professional support and valuable suggestions during the planning and development of this research work. I would like to offer my special thanks to Dr. Pat Mazik, Dr. Mike Strager, Dr. Jered Studinski, and Dr. Rich Raesly for their insight and encouragement as members of my graduate committee. Each offered a unique perspective and helpful advice and assistance for this project and my professional career. I would also like to especially thank Dr. Donald Brown for all of his advice, guidance, and patience. I cannot thank him enough for all of the time and effort that he put into this project. I would like to thank my fellow graduate students, particularly Patricia Thompson, Joni Aldinger, Dustin Smith, Corbin Hilling, and Ross Andrew for assistance with my research and their friendships that have made my time in West Virginia that much more enjoyable. I would like to extend special thanks to Becky Nestor, not only for her help making everything in my life run smoother, but also for her ability to make the COOP feel a little bit like a home away from home. Finally, I would especially like to thank my family and close friends for their love, encouragement, and support throughout my graduate career. 
CHAPTER 1: A Paired-Laser Photogrammetric Method for in situ Length Measurement of Benthic Fishes

This chapter has been formatted and published in the North American Journal of Fisheries Management, and can be cited as follows:

Rizzo, A. A., S. A. Welsh, and P. A. Thompson. 2017. A paired-laser photogrammetric method for in situ length measurements of benthic fishes. North American Journal of Fisheries Management 37:16-22. 
Abstract. - Photogrammetry, a technique to obtain measurements from photographs, may be a valid method for measuring lengths of rare, threatened, or endangered species. Photogrammetric methods of measurement are nonintrusive and reduce the possibility of physical damage or physiological stress associated with the capture and handling of individuals. We evaluated precision and accuracy of photogrammetric length measurements relative to board measurements of Greenside Darters Etheostoma blennioides and Variegate Darters Etheostoma variatum in an aquarium and applied photogrammetry in a field study of the Diamond Darter Crystallaria cincotta, a federally-listed endangered species. Digital photographs were taken of each individual using a waterproof camera equipped with two parallel lasers. Photogrammetric length measurements were digitized with ImageJ software. Agreement between board and photogrammetric measurements were high for Greenside and Variegate darters. The magnitude of differences was small between direct and photogrammetric measurements; ranging from $0.6 \%$ - 3.1\% difference, depending on the species measured and the type of measurement taken. These results support photogrammetry as a useful method for obtaining length measurements of benthic stream fishes. Photogrammetric methods allowed for length measurements and an assessment of length frequency of 199 Diamond Darters, informative data for management that could not be collected with conventional measuring board methods. 
Measuring fish lengths is common practice for research and management of fish populations. Measured lengths include total length (TL), standard length (SL), or fork length (FL) (Anderson and Neumann 1996). The most common methods for obtaining fish lengths involve direct measurements obtained from tape measures, calipers, or measuring boards. Direct measurements of length require capturing and handling of individuals, which may be prohibited for legally-protected fish, even though length data are still needed to understand population dynamics and inform management efforts.

As alternatives to physical measurements, fish lengths have been measured with nonintrusive methods, such as visual assessment (Harvey et al. 2001; Edgar et al. 2004), sonar acoustic cameras (Mueller et al. 2006), and photogrammetry techniques (Welsh and Aldinger 2014); including paired-laser photogrammetry (Rochet et al. 2006; Deakos 2010), stereo-video equipment (Bower et al. 2011; Shortis et al. 2013; Langlois et al. 2015), and underwater video with paired lasers (Yoshihara 1997). Nonintrusive methods of fish measurement are useful when it is difficult or undesirable to capture individuals with conventional sampling gear, such as in deep sea environments (Dunlop et al. 2015), at fish passage facilities (Welsh and Aldinger 2014), when fishes are too large to capture, such as Whale Sharks Rhincodon typus (Rohner et al. 2011), when fish are sensitive to stress of capture and handling (Molinero and Gonzalez 1995; Snyder 2003), and for protected areas or protected species (Harvey et al. 2001, Jack and Wing 2010). Although nonintrusive methods are useful in certain situations, an understanding of precision and accuracy of nonintrusive length measurements is needed for each application (Pfister and Goulet 1999; Rochet et al. 2006).

Paired-laser photogrammetry is a nonintrusive method which has been shown to provide precise and accurate measurements of animal lengths (Bergeron 2007; Deakos 2010). In paired- 
laser photogrammetry, the beams of two parallel lasers (attached to a camera) provide a measurement scale for determining the size of objects within the image frame. Rochet et al. (2006) reported minimal measurement errors when using laser photogrammetry to measure fishes that were sessile or lying immobile on the substrate, supporting the usefulness of this method for measuring benthic organisms. To our knowledge, paired-laser photogrammetry has not been evaluated on small benthic fishes in riverine environments.

Our study objectives were to evaluate paired-laser photogrammetry as a nonintrusive alternative to the capture, handling, and direct measurement of small, benthic fishes. Specifically, we used two abundant species, the Variegate Darter Etheostoma variatum and the Greenside Darter Etheostoma blennioides, to evaluate the accuracy and precision of photogrammetric length measurements in comparison with physical length measurements obtained by use of a measuring board. We then applied this technique in the field to collect length data to inform conservation and management efforts of the federally endangered Diamond Darter Crystallaria cincotta.

Methods

Measurement of Variegate and Greenside Darters. - Variegate Darters $(\mathrm{n}=70)$ and Greenside Darters $(\mathrm{n}=70)$ were collected from Dunkard Creek, WV, and lengths of individuals were measured with both photogrammetry and a metric measuring board. Underwater digital photographs for photogrammetry were taken inside an 80 liter aquarium using a waterproof Panasonic Lumix DMC-TS5 camera paired with two parallel Z-bolt green lasers (Figure 1). To 
reduce spooking fish with the laser beams, we spaced the two lasers by $152.4 \mathrm{~mm}$ ( 6.0 inches). The aquarium had $0.5 \mathrm{~m}$ water depth and small gravel as benthic substrate.

We photographed fish, which were resting on the substrate, from a dorsal view, because a lateral view may result in measurement bias owing to fish orientation and lateral flexion (Harvey et al. 2002; Karpov et al. 2009). The fish were about $35 \mathrm{~cm}$ away from the camera. The dorsal view allowed for measurement of TL, but not SL or FL. The upper and lower lobes of the caudal fin are often compressed dorsoventrally for TL; however, because we would not be able to accomplish this through photo analysis, TL was measured with the caudal fin in a natural position (Figure 2). Additionally, we measured the distance from the tip of the snout to the insertion of the first caudal fin ray, hereafter referred to as body length (BL, Figure 2). The BL measurement was included because the insertion of the first caudal fin ray (from dorsal view) is a well-defined anatomical landmark, and we were concerned that TL measurements would be influenced if the translucent end of the caudal fin was not well-defined in photographs. By comparing $\mathrm{BL}$ and $\mathrm{TL}$ we were able to examine measurement bias associated with the uncertainty in delineation of anatomical landmarks for measurement. For each individual, $\mathrm{BL}_{1}$ and $\mathrm{TL}_{1}$ were measured with a metric measuring board, and $\mathrm{BL}_{2}$ and $\mathrm{TL}_{2}$ were measured photogrammetrically by digitizing via the segmented-line measurement option within ImageJ software (Schneider et al. 2012; Figure 3). The measurement scale for the digital image was set based on the width between the two parallel lasers. Measurements from a metric measuring board can also have bias (Bunch et al. 2013), but for our analysis, we assumed that these measurements were accurate and unbiased. 
Agreement and error in length measurements. - Agreement between direct and photogrammetric measurements was evaluated using concordance correlation coefficients (CCCs). The CCC is a commonly used assessment of agreement between two measurement methods, with values ranging from 1 (perfect agreement) to -1 (perfect disagreement; Lin et al. 2002, 2007; Carrasco et al. 2013). The CCC is the product of precision and accuracy, where estimates of precision are based on the Pearson correlation coefficient and estimates of accuracy are based on a bias correction factor. McBride (2005) categorized the strength of agreement for CCC as follows: almost perfect $(\mathrm{CCC}>0.99)$, substantial $(0.95-0.99)$, moderate $(0.90-0.95)$, and poor $(<0.90)$. We computed $C C C$ values for $\mathrm{BL}_{1}$ versus $\mathrm{BL}_{2}$, and $\mathrm{TL}_{1}$ versus $\mathrm{TL}_{2}$ using the 'epi.ccc' metric in the package 'epiR' (Stevenson et al. 2015) in Program R (R Core Team 2014). Descriptive pairwise plots of $\mathrm{BL}_{1}$ versus $B L_{2}$, and $\mathrm{TL}_{1}$ versus $\mathrm{TL}_{2}$ (each with a $45^{\circ}$ reference line) provided a visual aid for interpretation of the CCC agreement between measurement methods (Lin 1989). Further, error in length measurements were calculated for $\mathrm{BL}_{2}$ and $\mathrm{TL}_{2}$ by looking at the differences: $\mathrm{BL}_{2}$ minus $\mathrm{BL}_{1}$ and $\mathrm{TL}_{2}$ minus $\mathrm{TL}_{1}$, respectively. Error values of each were plotted against their corresponding direct measurement $\left(\mathrm{BL}_{1}\right.$ or $\left.\mathrm{TL}_{1}\right)$ to determine if darter size influences residuals. In addition, linear regression was used to assess if measurement errors were related to darter length. Mean $\pm \mathrm{SE}$ of error values was also calculated for $\mathrm{BL}_{2}$ and $\mathrm{TL}_{2}$.

Measurement and Assessment of Diamond Darter Size Structure.—During 2015, Diamond Darters were observed at three sites on the Elk River, WV, using a nighttime spotlight sampling approach described by Welsh et al. (2013). Each Diamond Darter was photographed using the camera and pair-laser as described previously. Diamond Darters were photographed during five 
sampling periods, including 19-22 May (n=55), 3-6 August ( $\mathrm{n}=18), 27-30$ August (n=63), 1720 September $(n=47)$, and 16-19 October $(n=16)$. All three sites were sampled during each time period. The likelihood of repeat observations and photographs of the same individual was low for each sampling period, but was expected to be high among sampling periods.

To examine photogrammetric measurements of Diamond Darters, length-frequency histograms were created for each sampling event to aid in identifying potential cohorts. To analyze the histograms and identify potential cohorts we used the modal progression analysis in the software program FAO-ICLARM Stock Assessment Tools (FiSAT-II version 1.2.2) (Gayanilo et al. 2005). This program uses Bhattacharya's method to help identify and separate normal distributions that are found within a mixture of distributions in length frequency data. This method generated mean lengths and standard deviations for each cohort.

Results

Photogrammetric measurements $\left(\mathrm{BL}_{2}\right.$ and $\left.\mathrm{TL}_{2}\right)$ of Variegate and Greenside Darters were accurate, but with a slight systematic negative bias. The CCCs for $\mathrm{BL}_{1}$ versus $\mathrm{BL}_{2}$, and $\mathrm{TL}_{1}$ versus $\mathrm{TL}_{2}$, exceeded 0.94 for both species (Table 1, Figures 4 and 5). Measurements of $\mathrm{BL}_{1}$ and $\mathrm{BL}_{2}$ were less precise but more accurate than those of $\mathrm{TL}_{1}$ and $\mathrm{TL}_{2}$ for Variegate and Greenside darters (Table 1). A plot of $\mathrm{BL}_{2}$ and $\mathrm{TL}_{2}$ errors for both species depicted negative systematic shifts (bias; Figures 4 and 5), with TLs being more negatively biased than BLs. The mean of BL 2 error was $-0.303 \mathrm{~mm}(\mathrm{SE}=0.40 \mathrm{~mm})$ and $-1.069 \mathrm{~mm}(\mathrm{SE}=0.38 \mathrm{~mm})$ for Variegate and Greenside darters, respectively. The mean of $\mathrm{TL}_{2}$ error was $-1.926 \mathrm{~mm}(\mathrm{SE}=0.29 \mathrm{~mm})$ and - 
$1.865 \mathrm{~mm}(\mathrm{SE}=0.33)$ for Variegate and Greenside darters, respectively. Measurement errors were not related to darter size for either species or measurement $(\mathrm{P}>0.05)$.

The magnitude of differences was small between direct and photogrammetric measurements. For Greenside Darters, the mean of $\mathrm{BL}_{2}($ mean $\pm \mathrm{SE}=49.4 \pm 1.0 \mathrm{~mm})$ differed by $1.9 \%$ from mean $\mathrm{BL}_{1}(50.4 \pm 1.0)$. For Variegate Darters, the mean of $\mathrm{BL}_{2}(53.2 \pm 1.2 \mathrm{~mm})$ differed by $0.6 \%$ from mean $\mathrm{BL}_{1}(53.5 \pm 1.1)$. When analyzing total length measurements, Greenside Darter's mean of $\mathrm{TL}_{2}(57.4 \pm 1.2)$ differed by $3.0 \%$ from mean $\mathrm{TL}_{1}(59.2 \pm 1.2)$. For Variegate Darters, the mean of $\mathrm{TL}_{2}(61.7 \pm 1.4)$ differed by $3.1 \%$ from mean $\mathrm{TL}_{1}(63.7 \pm 1.4)$.

Temporal Assessment of Size Structure for Diamond Darters

A total of 199 photographs of Diamond Darters were taken during five seasonal sampling events in May through October of 2015. Decomposition of length-frequency histograms by the program FiSAT II identified one distinct cohort during each sampling event (Figure 6). Based on the modal distribution and progression through time this cohort appeared to persist in the glide habitat through all five seasonal sampling events. The mean length of the Diamond Darters increased throughout the sampling season (May-October) at a rate of approximately 4.05 $\mathrm{mm} / \mathrm{month}$. Given a lack of age/length data for Diamond Darters, and an absence of multiple cohorts in our sample, it is difficult to speculate upon the age of the cohort present. 
Discussion

The CCCs for TLs and BLs were similarly high for both the species in the lab study, indicating that the photogrammetric technique was an effective method for measuring these darter species. The different measurements varied in their precision and accuracy, with the $\mathrm{TL}_{2} \mathrm{~S}$ being more precise than $\mathrm{BL}_{2} \mathrm{~S}$ but less accurate and slightly biased. $\mathrm{TL}_{2} \mathrm{~S}$ for Variegate and Greenside Darters showed a slightly negative bias, where the mean error was $-1.9 \mathrm{~mm}$ for both species compared with an unbiased mean of zero. This small measurement error $(<2.0 \mathrm{~mm})$ was similarly noted in other parallel laser photogrammetry studies when photographing benthic organisms between $20-140 \mathrm{~mm}$ in length (Dunlop et al. 2015). Length bias was also determined to be an issue in an American Eel photogrammetry study conducted by Welsh and Aldinger (2014); however, in their study, measurements showed a positive bias. In our study, the bias in $\mathrm{TL}_{2} \mathrm{~s}$ may have been the result of caudal membranes being more transparent towards their tip, causing human error when measuring with ImageJ. Alternatively, measurement error could be the product of some type of digital image distortion or aberration resulting from the camera lens or the aqueous medium (Mallon and Whelan 2007; Alemán-Flores et al. 2014).

While this measurement technique has been shown to be useful, water conditions can have a large impact on the quality of digital images. Water turbidity and depth are complicating variables that can greatly reduce the quality of the images, subsequently leading to larger measurement errors (Deakos 2010; Rohner et al. 2011). For our field study, sampling was conducted during periods when both water level and turbidity were lower; allowing for higher detection of Diamond Darters and higher quality images. We used the camera flash underwater to illuminate the Diamond Darters during photographs, but this method was often hindered by the light-scattering effect of suspended particles in the water column. Photographs of Diamond 
Darters, however, were successful when a headlamp spotlight was used for illumination. Another complication that we encountered during our field study was the occasional light scattering effects of fog when trying to illuminate the fish for photographs. As temperature dropped over the course of the night's sampling, occasionally banks of fog would form over the river influencing our ability to illuminate the darters using head lamps. During these high fog events, photographs were generally taken in closer proximity to the fish and more light-power was needed to illuminate the fish in order to obtain images that were of high enough quality to obtain size data. During these events multiple images were taken of the same individual to increase the likelihood of getting a useable, high-quality image.

In addition to considering environmental conditions that influence the quality of digital images, the behavior of the study organism is also a complicating factor. Photographs for photogrammetry generally work well on organisms that are benthic, sedentary, and not easily disturbed. Rochet et al. (2006) found that mobility of subjects was their main source of error when using underwater photogrammetry techniques (i.e., parallel lasers technique and auto focus video camera). In our study, the Diamond Darter was not easily disturbed by the photographic process of using flashes or spotlights. Diamond Darter behavior, however, differed depending on the time of sampling, where individuals were more easily disturbed during early morning $(<2$ hours before sunrise).

Photographic angle is another important factor. For example, photographs taken at 90 degrees to the long axis of the organism have been shown to have minimal errors compared to those that deviate from this angle (Webster et al. 2010). Aquarium photographs of Greenside and Variegate darters were relatively easy to orient perpendicularly to the fish's long axis. In the field, the preferred photographic angle may not always be possible, however, the benthic, 
sedentary Diamond Darters in our study always allowed for the optimal perpendicular photographing angle. Furthermore, given that we photographed fishes from a dorsal view, body flexure of fishes did not affect our measurements. This technique may also be applicable to nonbenthic fish species; however, additional studies should be conducted to determine if measurement errors vary with this factor.

In our study total length appeared to be the most appropriate measurement to use; higher precision and similar mean errors between the two surrogate species make this measurement more applicable to other benthic species - especially if used with a correction factor. Although we did not assess length measurement error in our field application of paired-laser photogrammetry, we speculate that error for Diamond Darters would be very small as was found for the two surrogate species. Photogrammetric measurements of total length were used to gauge changes in population size structure of Diamond Darters within sampled glide areas. From these digital images we were able to detect changes in the mean length of Diamond Darters during a spring to fall time period, and document information on the size range of Diamond Darters using glide habitat. Previously, length data from caliper measurements were available from only seven Elk River individuals (Welsh and Wood 2008), thus this study of 199 images of Diamond Darters provides a larger sample size of length data to inform management decisions of this endangered species. 


\section{Acknowledgements}

The authors wish to thank NiSource and U.S. Fish and Wildlife Service for funding. We thank Joni Aldinger, Brian Crabill, Kevin Lambert, and Rich Raesly for field assistance. Any use of trade, firm, or product names is for descriptive purposes only and does not imply endorsement by the U.S. Government. This study was performed under the auspices of West Virginia University IACUC protocol 12-0205. 
References

Anderson, R. O. and R. M. Neumann. 1996. Length, weight, and associated structural indices. Pages 447-482 in B. R. Murphy and D. W. Willis, eds. Fisheries Techniques, Second Edition. American Fisheries Society, Bethesda, Maryland.

Alemán-Flores, M., L. Alvarez, L. Gomez, and D. Santan-Cedrés. 2014. Line detection in images showing significant lens distortion and application to distortion correction. Pattern Recognition Letters 36:261-271.

Bergeron, P. 2007. Parallel lasers for remote measurements of morphological traits. Journal of Wildlife Management 71:289-292.

Bower, M. R., D. B. Gaines, K. P. Wilson, J. G. Wullschleger, M. C. Dzul, M. C. Quist, and S. J. Dinsmore. 2011. Accuracy and precision of visual estimates and photogrammetric measurements of the length of a small-bodied fish. North American Journal of Fisheries Management 31: 138-143.

Bunch, A. J., C. J. Walters, L. G. Coggins, Jr. 2013. Measurement error in fish lengths: evaluation and management applications. Fisheries 38:320-326.

Carrasco, J. L., B. R. Phillips, J. Puig-Martinez, T. S. King, and V. M. Chinchilli. 2013. Estimation of the concordance correlation coefficient for repeated measures using SAS and R. Computer Methods and Programs in Biomedicine 109:293-304. 
Deakos, M. H. 2010. Paired-laser photogrammetry as a simple and accurate system for measuring the body size of free-ranging manta rays Manta alfredi. Aquatic Biology $10: 1-10$.

Dunlop, K. M., L. Al. Kuhnz, H. A. Ruhl, C. L. Huffard, D. W. Caress, R. G. Henthorn, B. W. Hobson, P. McGill, and K. L. Smith Jr. 2014. An evaluation of deep-sea benthic megafauna length measurements obtained with laser and stereo camera methods. DeepSea Research I 96:38-48.

Edgar, G. J., N. S. Barrett, and A. J. Morton. 2004. Biases associated with the use of underwater visual census techniques to quantify the density and size-structure of fish population. Journal of Experimental Marine Biology and Ecology 308:269-290.

Gayanilo, F. C. Jr., P. Sparre, P. Pauly. 2005. FAO-ICLARM stock assessment tools (FiSAT II). Revised version. User's manual. Food and Agriculture Organization of the United Nations, Rome. Available at http://www.fao.org/docrep/ 009/y5997e/y5997e00.htm

Harvey, E., D. Fletcher, and M. Shortis. 2001. A comparison of the precision and accuracy of estimates of reef-fish lengths determined visually by divers with estimates produced by a stereo-video system. Fishery Bulletin 99:63-71.

Harvey, E., M. Shortis, M. Stadler, and M. Cappo. 2002. A comparison of the accuracy and precision of measurements from single and stereo-video systems. Marine Technological Society Journal 36:38-49.

Jack, L. and S. R. Wing. 2010. Maintenance of old-growth size structure and fecundity of the red rock lobster Jasus edwardsii among marine protected areas in Fiordland, New Zealand. Marine Ecology Progress Series 404:161-172. 
Karpov, K., N. J. Kogut, J. J. Geibel, 2009. Estimating fish length from vertical morphometric parameters. California Fish and Game 95:161-174.

Langlois, T. J., S. J. Newman, M. Cappoc, E. S. Harvey, B. M. Rome, C. L. Skepper, C. B. Wakefield. 2015. Length selectivity of commercial fish traps assessed from in situ comparisons with stereo-video: Is there evidence of sampling bias? Fisheries Research 161:145-155.

Lin, L. I. 1989. A concordance correlation coefficient to evaluate reproducibility. Biometrics 45:255-268.

Lin, L., A. S. Hedayat, B. Sinha, and M. Yang. 2002. Statistical methods in assessing agreement: models, issues and tools. Journal of the American Statistical Association 97:257-270.

Lin, L., A. S. Hedayat, and W. Wu. 2007. A unified approach for assessing agreement for continuous and categorical data. Journal of Biopharmaceutical Statistics 17:629-652.

Mallon, J., and P. F. Whelan. 2007. Calibration and removal of lateral chromatic aberration in images. Pattern Recognition Letters 28:125-135.

McBride, G. B. 2005. A proposal for strength-of-agreement criteria for Lin's Concordance Correlation Coefficient. National Institute of Water and Atmospheric Research Client Report: HAM2005-062.

Molinero, A. and J. Gonzalez. 1995. Comparative effects of MS 222 and 2-phenoxyethanol on gilthead sea bream (Sparus aurata L.) during confinement. Comparative Biochemistry and Physiology A-Comparative Physiology 111A:405-414. 
Mueller, R., R. Brown, H. Hop, L. Moulton. 2006. Video and acoustic camera techniques for studying fish under ice: a review and comparison. Reviews in Fish Biology and Fisheries $16: 213-226$.

Pfister, R. P. and D. Goulet. 1999. Nonintrusive video technique for in situ sizing of coral reef fishes. Copeia 3:789-793.

R Core Team. 2014. R: A language and environment for statistical computing. R Foundation for Statistical Computing, Vienna, Austria. URL http://www.R-project.org/.

Rochet, M. J., J. F. Cadiou, and V. M. Trenkel. 2006. Precision and accuracy of fish length measurements obtained with two visual underwater methods. Fishery Bulletin 104:1-9.

Rohner, C. A., A. J. Richardson, A. D. Marshall, S. J. Weeks, and S. J. Pierce. 2011. How large is the world's largest fish? Measuring whale sharks Rhincodon typus with laser photogrammetry. Journal of Fish Biology 78:378-385.

Schneider, C. A., W. S. Rasband, and K. W. Eliceiri. 2012. NIH Image to ImageJ: 25 years of image analysis. Nature Methods 9:671-675.

Shortis, M. R., M. Ravanbakhsh, F. Shafait, E. S. Harvey, A. Mian, J. W. Seager, P. F. Culverhouse, D. E. Cline, and D. R. Edgington. 2013. A review of techniques for the identification and measurement of fish in underwater stereo-video image sequences. Videometrics, Range Imaging, and Applications XII, SPIE Vol. 8791, paper 0G. The International Society for Optical Engineering, Bellingham WA, USA.

Snyder, D. E. 2003. Invited overview: conclusions from a review of electrofishing and its harmful effects on fish. Reviews in Fish Biology and Fisheries 13:445-453. 
Stevenson, M., T. Nunes, C. Heuer, J. Marshall, J. Sanchez, R. Thornton, J. Reiczigel, J. Robison-Cox, P. Sebastiani, P. Solymos, K. Yoshida, G. Jones, S. Pirikahu, and S. Firestone. 2015. epiR: Tools for the Analysis of Epidemiological Data. R package version 0.9-69. http://CRAN.R-project.org/package=epiR-

Webster, T., S. Dawson, E. Slooten. 2010. A simple laser photogrammetry technique for measuring Hector's dolphins (Cephalorhynchus hectori) in the field. Marine Mammal Science 26:296-308.

Welsh, S. A. and J. L. Aldinger. 2014. A semi-automated method for monitoring dam passage of upstream migrant yellow-phase American Eels. North American Journal of Fisheries Management 34:702-709.

Welsh, S.A., D.M. Smith, and N.D. Taylor. 2013. Microhabitat use of the diamond darter. Ecology of Freshwater Fish 22:587-595.

Welsh, S. A. and R. M. Wood. 2008. Crystallaria cincotta, a new species of darter (Teleostei: Percidae) from the Elk River of the Ohio River drainage, West Virginia. Zootaxa 1680:62-68.

Yoshihara, K. 1997. A fish body length measuring method using an underwater video camera in combination with laser discharge equipment. Fisheries Science 63:676-680. 


\section{Figure Captions}

Figure 1. Photograph of our camera/ parallel-lasers set-up. The camera was a waterproof Panasonic Lumix DMC-TS5 camera paired with two parallel Z-bolt green lasers. The lasers were spaced by $152.4 \mathrm{~mm}$ (6.0 inches).

Figure 2. Measurements showing body length (BL) and total length (TL). Image of Diamond Darter drawn by Stuart A. Welsh.

Figure 3. Screen shot of a digital image of a Diamond Darter being analyzed in ImageJ.

Figure 4. Concordance correlation coefficients (CCCs) for (A) Variegate Darter body lengths (BLs) obtained from photogrammetric measurements $\left(\mathrm{BL}_{2}\right)$ compared with BLs measured using a measuring board $\left(\mathrm{BL}_{1}\right) ; \mathrm{CCC}\left[\mathrm{CL}_{\mathrm{L}}-\mathrm{CL}_{\mathrm{U}}\right]=0.941$ [0.909-0.962]; (B) Total lengths (TLs) obtained from photogrammetric measurements $\left(\mathrm{TL}_{2}\right)$ compared with TLs using a metric measuring board $\left(\mathrm{TL}_{1}\right)$; $\mathrm{CCC}\left[\mathrm{CL}_{\mathrm{L}}-\mathrm{CL}_{\mathrm{U}}\right]=0.950$ [0.922-0.968].

Figure 5. Concordance correlation coefficients (CCCs) for (A) Greenside Darter body lengths (BLs) obtained from photogrammetric measurements $\left(\mathrm{BL}_{2}\right)$ compared with BLs measured using a measuring board $\left(\mathrm{BL}_{1}\right) ; \mathrm{CCC}\left[\mathrm{CL}_{\mathrm{L}}-\mathrm{CL}_{\mathrm{U}}\right]=0.952[0.924-0.969 ;(\mathbf{B})$ Total lengths (TLs) obtained from photogrammetric measurements $\left(\mathrm{TL}_{2}\right)$ compared with TLs using a metric measuring board $\left(\mathrm{TL}_{1}\right) ; \mathrm{CCC}\left[\mathrm{CL}_{\mathrm{L}}-\mathrm{CL}_{\mathrm{U}}\right]=0.945[0.915-0.964]$.

Figure 6. Length frequency histograms for Diamond Darters during each sampling season. Size distribution curves are overlaid based on the cohort means $(\mu)$ and standard deviations (s) identified using Bhattacharya's Method in the program FISAT II. Mean and standard deviation are in reference to those individuals found only within the identified cohorts. 
Table 1. Different measurement values that are involved in assessing precision and accuracy of the photogrammetric measurements. The concordance correlation coefficient contains a measurement of precision and accuracy and can be determined by multiplying the Pearson correlation coefficient with the bias correction factor.

\begin{tabular}{lccccc}
\hline Measurement & Purpose & $\begin{array}{c}\text { Variegate } \\
\text { Darter BL }\end{array}$ & $\begin{array}{c}\text { Variegate } \\
\text { Darter TL }\end{array}$ & $\begin{array}{c}\text { Greenside } \\
\text { Darter BL }\end{array}$ & $\begin{array}{c}\text { Greenside } \\
\text { Darter TL }\end{array}$ \\
\hline $\begin{array}{l}\text { Pearson } \\
\text { correlation } \\
\text { coefficient }\end{array}$ & Measure of precision & 0.947 & 0.964 & 0.960 & 0.964 \\
$\begin{array}{l}\text { Bias correction } \\
\text { factor }\end{array}$ & Measure of accuracy & 0.994 & 0.985 & 0.992 & 0.981 \\
$\begin{array}{l}\text { Concordance } \\
\text { Correlation } \\
\begin{array}{l}\text { Coefficient } \\
\text { (CCC) }\end{array}\end{array}$ & $\begin{array}{c}\text { Measurement of } \\
\text { precision } \text { and } \\
\text { accuracy }\end{array}$ & 0.941 & 0.950 & 0.952 & 0.945 \\
\hline
\end{tabular}




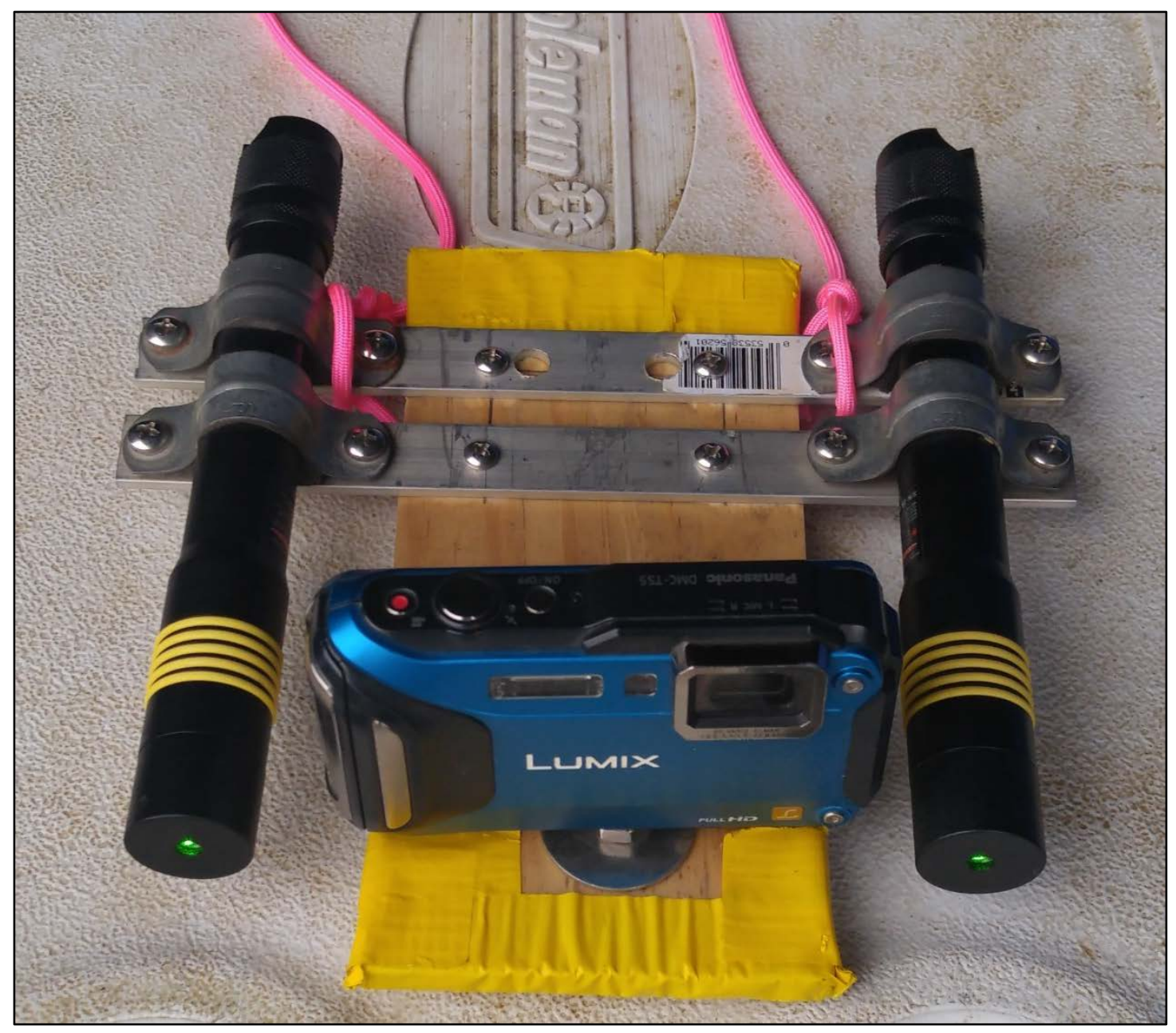

Figure 1. 


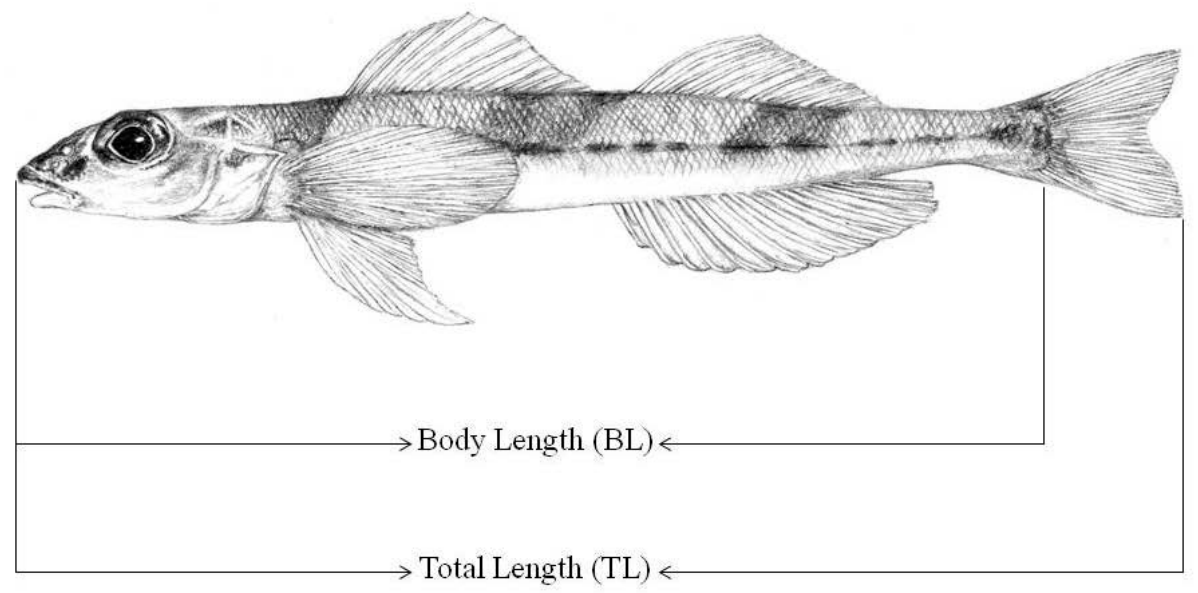

Figure 2. 


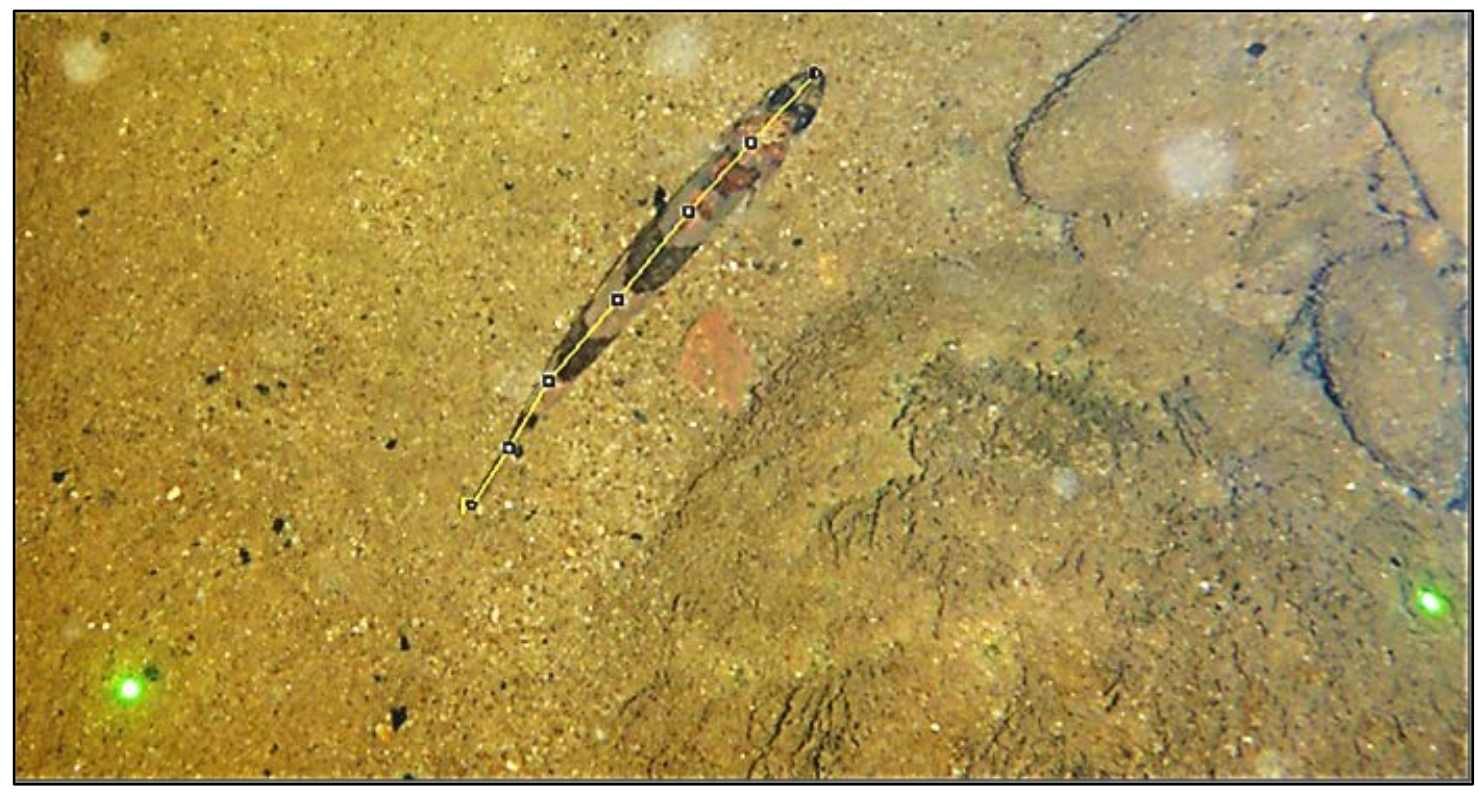

Figure 3. 

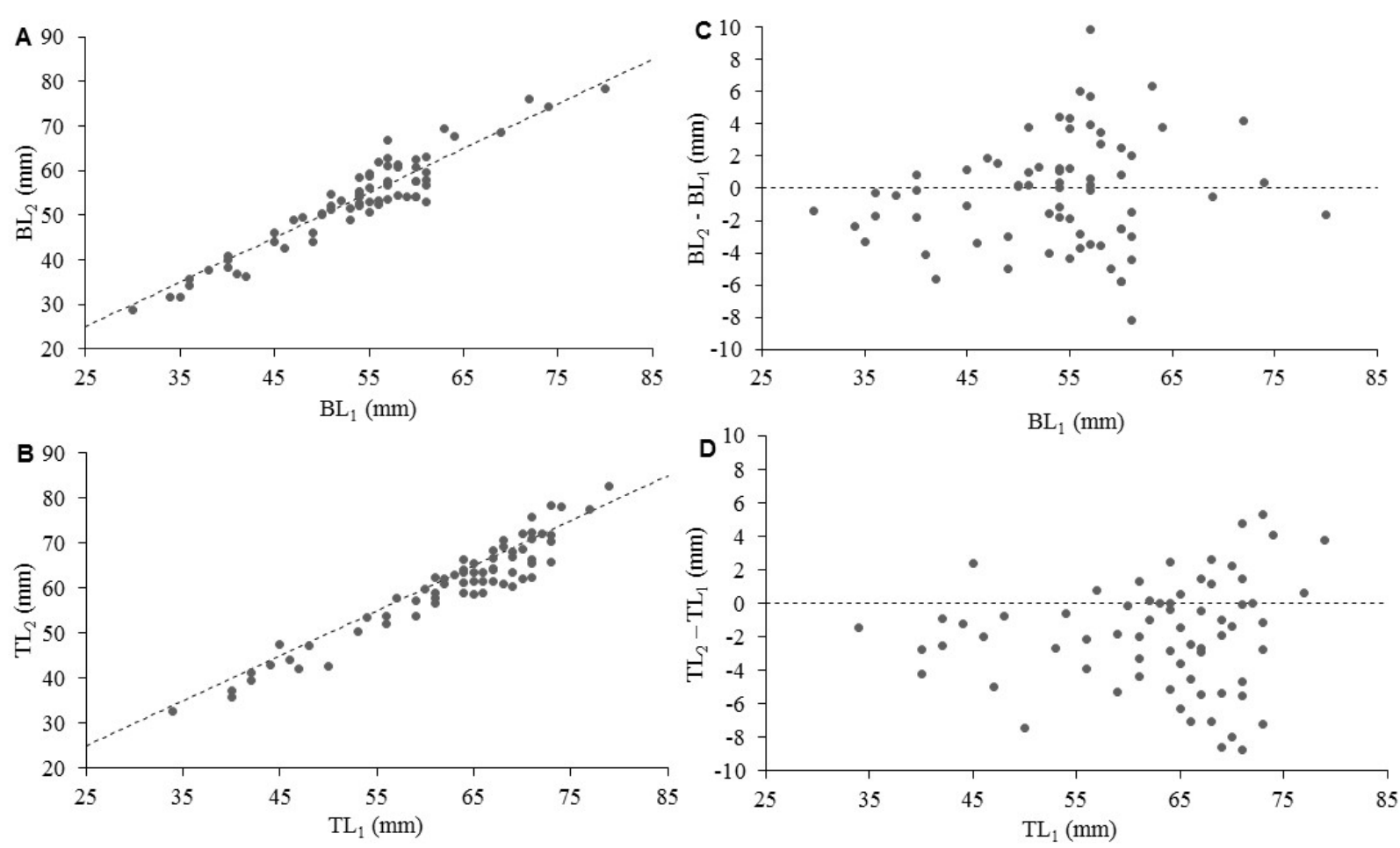

Figure 4. 

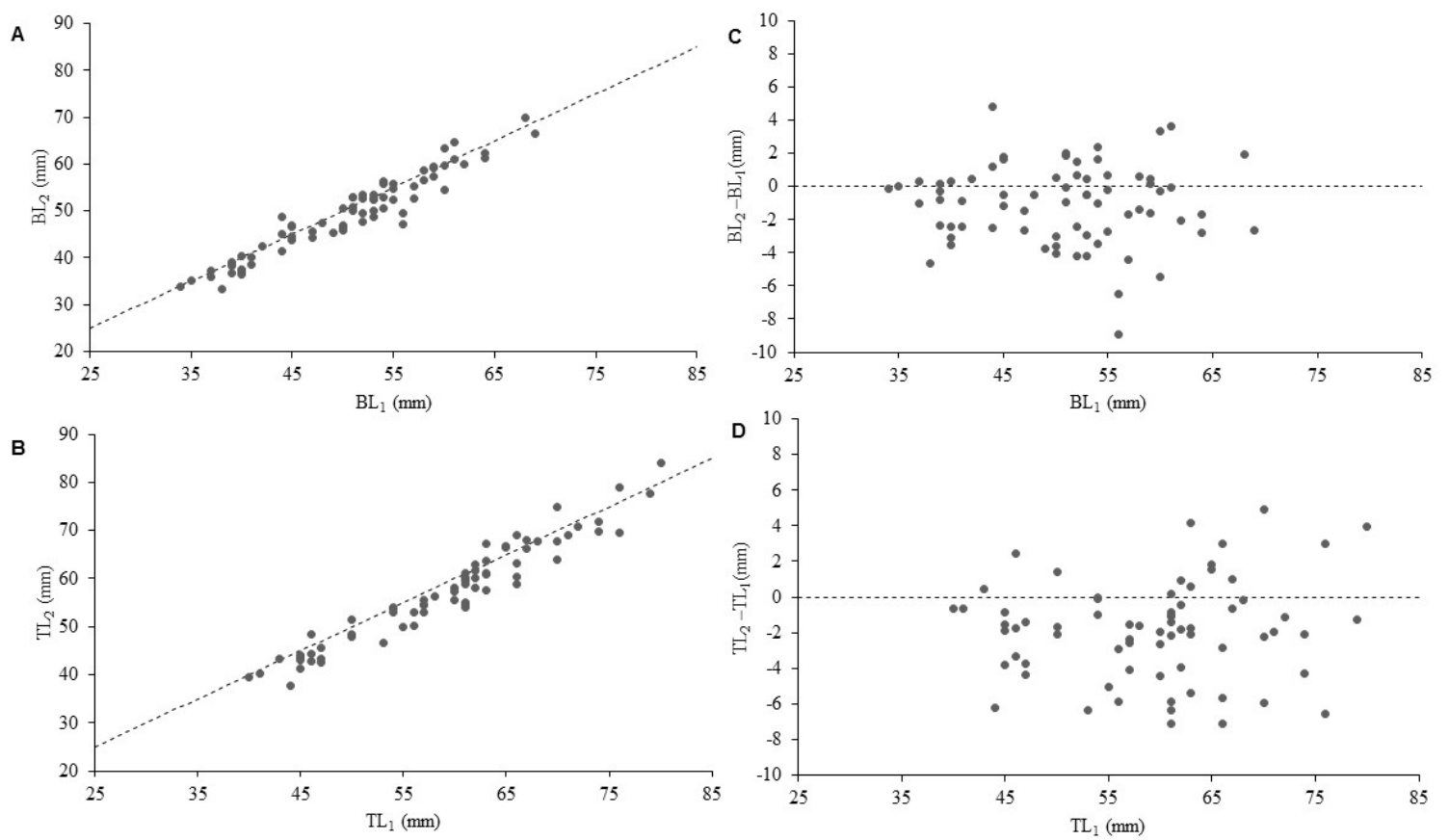

Figure 5. 

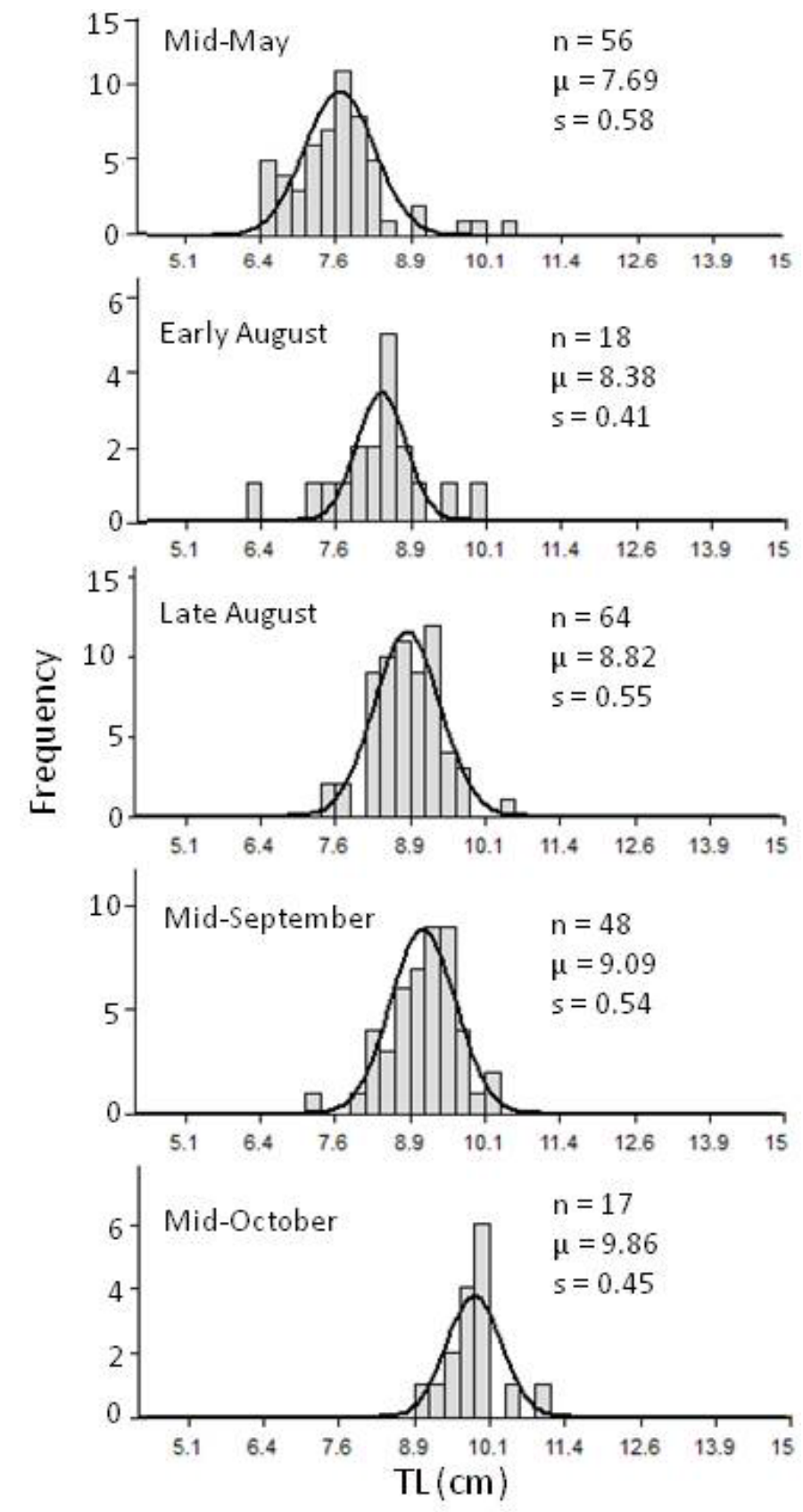

Figure 6. 
CHAPTER 2: Factors influencing detection of the federally endangered Diamond Darter Crystallaria cincotta: implications for long-term monitoring strategies

This chapter has been formatted and published in the American Midland Naturalist, and can be cited as follows:

Rizzo, A. A., D. J. Brown, S. A. Welsh, and P. A. Thompson. 2017. Factors influencing detection of the federally endangered Diamond Darter Crystallaria cincotta: Implications for long-term monitoring strategies. American Midland Naturalist 178:123-131. 
ABSTRACT.-Population monitoring is an essential component of endangered species recovery programs. The federally endangered Diamond Darter Crystallaria cincotta is in need of an effective monitoring design to improve our understanding of its distribution and track population trends. Because of their small size, cryptic coloration, and nocturnal behavior, along with limitations associated with current sampling methods, individuals are difficult to detect at known occupied sites. Thus, research is needed to determine if survey efforts can be improved by increasing probability of individual detection. The primary objective of this study was to determine if there are seasonal and diel patterns in Diamond Darter detectability during population surveys. In addition to temporal factors, we also assessed 5 habitat variables that might influence individual detection. We used $N$-mixture models to estimate site abundances and relationships between covariates and individual detectability, and ranked models using Akaike's information criteria. During 2015, three known occupied sites were sampled 15 times each between May and Oct. The best supported model included WATER TEMPERATURE as a quadratic function influencing individual detectability, with temperatures around $22 \mathrm{C}$ resulting in the highest detection probability. Detection probability when surveying at the optimal temperature was approximately $6 \%$ and $7.5 \%$ greater than when surveying at $16 \mathrm{C}$ and $29 \mathrm{C}$, respectively. TIME OF NIGHT and DAY OF YEAR were not strong predictors of Diamond Darter detectability. The results of this study will allow researchers and agencies to maximize detection probability when surveying populations, resulting in greater monitoring efficiency and likely more precise abundance estimates. 


\section{INTRODUCTION}

Population monitoring is an essential component of endangered species recovery programs. One species for which monitoring is needed is the federally endangered Diamond Darter Crystallaria cincotta. It has been argued that there are two types of rare species: truly functional rare species and operationally rare species (McDonald, 2004). Truly functional rare species are those species that have a very small range and population size. Operationally rare species generally appear to be rare because they have sparse and/or clumped populations, are small, cryptic, or elusive, or current survey procedures are insufficient for detection (McDonald, 2004). The Diamond Darter is considered to be a rare species (USFWS, 2013). There is ample evidence that the Diamond Darter's geographic distribution is in fact small, indicating it is a truly functional rare species. However, because of the Diamond Darter's small size, cryptic coloration, nocturnal behavior, and seemingly patchy distribution, along with limitations associated with current sampling methods, the species may appear to be more rare than it actually is. This may have also contributed to its late discovery as a species in 2008. Museum specimens indicate the Diamond Darter was once distributed throughout the Ohio River Basin, but it is now believed to be extirpated from the Muskingum River in Ohio, the Ohio River in Ohio, Kentucky and Indiana, the Green River in Kentucky, and the Cumberland River drainage in Kentucky and Tennessee. Currently, it is known to exist only within the lower $50 \mathrm{~km}$ of the Elk River in West Virginia (Welsh \& Wood, 2008; Welsh et al., 2009; Welsh et al., 2014).

Studies have found that seasonal and diel plasticity in behavior and habitat use patterns of freshwater fish is common (Ali, 1992), and often strongly associated with environmental changes (Reeves et al., 2009). Seasonal plasticity in habitat use and behavior may help to increase survival and fecundity of fishes in dynamic, seasonally-changing systems, and has been observed 
in numerous species, including darters (Jones et al., 1984; Hlohowskyj \& Wissing, 1985;

Harding et al., 1998). Diel plasticity has also been observed in numerous species and is usually attributed to individuals seeking thermal, velocity, or predator refuge (Mundahl, 1990; Smith \& Fausch, 1997; Schaefer et al., 2003). Diel plasticity in behavior and habitat use has also been observed in fish species whose prey items become active during nocturnal periods (Reebs, 2002).

Failure to account for detection probability can be a major source of bias in presenceabsence and count survey data, potentially resulting in false determination of species absence and underestimation of abundance, respectively (MacKenzie et al., 2002; MacKenzie et al., 2006; Kéry \& Royle, 2016). Ultimately, not accounting for detection probability may lead to misinformed management decisions, which can prove costly for an endangered species. Most fish monitoring programs either use counts of organisms as proxies for abundance or employ capture-recapture or removal sampling techniques. These techniques can often be costly in terms of effort and resources and may not be possible depending on the study organism. In particular, use of these survey techniques (which involve capturing and handling individuals) may not be a viable option for threatened and endangered species.

$\mathrm{N}$-mixture models provide an alternative to traditional abundance estimation techniques by allowing abundance to be estimated without marking or removing individuals (Royle, 2004; Kéry \& Royle, 2016). Additionally, these models estimate detection probability independently from abundance, and thus allow for the inclusion of explanatory covariates for both parameters. This approach is appropriate when you have repeated count data or repeated detection/nondetection data from multiple sites and can assume that sites are closed to changes in mortality, recruitment, and migration over the sampling interval (Royle, 2004; Dail \& Madsen, 2011). $N$ mixture models have been used to estimate abundance of many wildlife species (e.g., Joseph et 
al., 2009; Couturier et al., 2013), as well as several fish species (e.g., Wenger \& Freeman, 2008; Kanno et al., 2014).

Our knowledge regarding the historic and current distribution and abundance of the Diamond Darter is based on museum specimens and field surveys conducted since 2011 using a recently developed search method (Welsh et al., 2013). These surveys have confirmed that Diamond Darters use glide habitat (i.e., those areas of the river immediately upstream of riffles). However, qualitative observations indicate detection probabilities at known occupied sites show diel variation. In addition, availability of Diamond Darters in glide habitat may vary seasonally.

The primary objective of this study was to determine if there is seasonal and diel variation in Diamond Darter detectability. Along with considering temporal factors, we also assessed 5 habitat variables that could influence detection of individuals. Our final objective was to estimate abundance at our study sites, resulting in the first site abundance estimates for the Diamond Darter.

\section{METHODS \\ Data Collection}

The Diamond Darter is presently known to exist only within the lower $50 \mathrm{~km}$ of the Elk River in West Virginia (Welsh \& Wood, 2008; Welsh et al., 2009; Welsh et al., 2014). Our study focused on three glide areas (sites) within their known geographical range (Fig. 1).These three sites were chosen because occupancy at these sites had previously been established, allowing us to focus on abundance and detection given known occupancy.

Sites were surveyed using a search method that employs the use of spotlighting at night with flashlights within wadeable sections of the river. This method has proven to be effective in glide habitats. These areas are shallow enough for a person to wade transects and have a smooth 
water surface, which allows the spotlighter to see through the water column to the substrate (Welsh et al., 2013). As a result of water level fluctuations in the river, the number of transects required to search a site varied by sampling night, with the range in the number of transects searched in a given night being 20-24 at Walgrove, 24-32 at Reamer, and 24-32 at Clendenin. Consequently, there was no standard number of transects sampled per sampling occasion. Counts of Diamond Darters were summed across all transects at a site to get a total count during a sampling occasion.

Potential diel variation in detectability was assessed by breaking up the time between dusk and dawn into three distinct time blocks based on time after sunset and time before sunrise. Sampling occurred $1 \mathrm{~h}$ after sunset, $2 \mathrm{~h}$ before sunrise, and in the middle of the night. The actual time of sampling varied throughout the summer as a result of day length changes. Because glide size varied among sites and depended on water levels, search times varied in order to thoroughly sample each glide area. Sampling took place in three-day blocks. All three sites were sampled each night and each site was sampled at a different time block each night.

Time of night that sampling occurred was modeled using HOURS AFTER SUNSET (h). To assess seasonal variation in detectability, we sampled in May, Aug., Sep., and Oct. (high river discharges prevented sampling during Jun. and Jul.), and modeled this covariate using DAY OF YEAR. The following covariates were recorded during each sampling event: WATER TEMPERATURE, WATER GAUGE HEIGHT at upstream gaging station, TURBIDITY, and SKY BRIGHTNESS. Temperature directly affects the metabolic rate of ectothermic organisms, and as a result, behavior and activity of these organisms often is contingent on the temperature of the surrounding environment (Ingersoll \& Claussen, 1984). WATER TEMPERATURE was included because of its potential to influence detection of the darter. 
Water gage height was included to capture the effects of water levels on detection. Water level can affect detection by: (1) decreasing the ability of the observer to see through deeper water (influencing detection when available), and (2) creating suboptimal habitat in glide areas as a result of increased velocity and other factors associated with higher water levels (influencing availability). Turbidity was included as a detection covariate because of its potential to affect both the behavior of the darter and the field of vision for the searchers. Most fish rely on their vision as their main source of sensory information, aiding in their ability to detect both predator and prey (Pitcher et al., 1993). Turbidity has been found to affect the visual abilities of fish; however, whether the effects are positive or negative largely depends on the species, the size class, and the interactive effects with available light (Utne-Palm, 2002; Stoner, 2004). Consequently, brightness of the sky (measured by a sky quality meter) was included as a covariate potentially influencing the behavior of the Diamond Darter, both on its own and as an interactive effect with turbidity (Utne-Palm, 2002). This interactive effect with turbidity may also influence observer detection of the darter and was included as a covariate for both reasons.

\section{DATA ANALYSES}

$N$-mixture models were used to estimate abundance and identify important variables influencing individual detection. A pairwise correlation analysis of all predictor variables was conducted to identify any multicollinearity prior to $\mathrm{N}$-mixture modeling. WATER TEMPERATURE was included in candidate models as a quadratic term because preliminary analyses indicated that the quadratic relationship with relative abundance was a better predictor than a simple linear relationship. DAY OF YEAR was included in candidate models as a linear term and a quadratic term because of the potential for different seasonal effects influencing detection. 
To estimate abundance at each site, we used a single-season $N$-mixture model (Kéry \& Royle, 2016), with a binomial distribution for the observation process. A single-season model was used to analyze surveys conducted from May through Oct. under the assumption that the population was closed during that period. Demographic closure was assumed based on analysis of population size structure throughout the season (Rizzo et al., 2017). Additionally, adjusted population estimates were similar throughout the sampling season, lending support to our assumption that our populations were closed. Research by Kendall (1999) suggests that if individuals occupy and vacate a site in a random manner, estimators used to explain detection and abundance/occupancy should remain unbiased. However, if there is random movement, resulting in the violation of geographic closure, then parameter values for detection and abundance/occupancy may be inaccurate. Inaccurate mean estimated probabilities would result in an increase in the variance of our estimates (MacKenzie et al., 2004).

A Poisson distribution was chosen for the state process after comparing Akaike Information Criterion $\left(\mathrm{AIC}_{\mathrm{c}}\right)$ values and residual diagnostic plots for 3 distributions (i.e., Poisson, zero-inflated Poisson, and negative binomial; Kéry \& Royle, 2016). Model goodnessof-fit was evaluated using a parametric bootstrap of the Pearson chi-square statistic (Mazerolle, 2016). The goodness-of-fit test indicated the data were overdispersed, and we accounted for this by inflating the estimated standard errors and $95 \%$ confidence intervals (CI) based on the $\hat{c}$ value (i.e., 4.7; Kéry \& Royle, 2016).

A total of 10 a priori models were constructed based on our knowledge of darter biology. The number of models included was partially restricted by the small sample size. Model complexity was minimized in an effort to make interpretation simple, allowing researchers to identify those variables most responsible for variation in individual Diamond Darter 
detectability. Because we were interested in estimating abundance by site, SITE was included as a covariate of abundance in all 10 models. All models, except one, included only one detection variable. The exception was a model that included the interactive effect of SKY BRIGHTNESS and TURBIDITY. SITE was also included in one model as a detection variable, allowing us to determine if there was evidence that detectability varied among sites due to factors that were not measured (Table 1).

Candidate models were ranked according to Akaike's information criteria corrected for small sample size $\left(\mathrm{AIC}_{\mathrm{c}}\right)$. The model with the lowest $\mathrm{AIC}_{\mathrm{c}}$ was considered to be the most parsimonious among the collection of candidate models, and all models within seven $\mathrm{AIC}_{\mathrm{c}}$ values of the minimum were considered to have some support (Burnham \& Anderson, 2002). A likelihood ratio test was used to verify that the best-fitting detection model was significantly better than the intercept-only detection model (Bolker et al., 2009). Abundances at all three sites were estimated using the best-fit model.

\section{RESUlts}

We completed 45 surveys over the 3 study sites and detected Diamond Darters during 41 of those surveys, resulting in a naive species detection probability of 0.91 . Counts at the three study sites ranged from 0 to 42 Diamond Darters detected during a single survey event. Predicted abundances varied widely among the three sites. The Clendenin site had the highest abundance $(\hat{\lambda}=96.1[58.9-156.8])$, followed by the Reamer site $(\hat{\lambda}=68.8$ [39.3-120.3]), and then the Walgrove site $(\hat{\lambda}=6.5[2.2-19.6])$.

The WATER TEMPERATURE model was the only detection model with substantial support $\left(\mathrm{AIC}_{\mathrm{c}}=353.5, w_{i}=0.996\right.$; Table 1$)$. The model had a positive coefficient for WATER TEMPERATURE $(\beta=0.5615$, s.e. $=0.05)$ and a negative coefficient for WATER TEMPERATURE ${ }^{2}(\beta=$ 
-0.0127 , s.e. $=0.00)$. Water temperatures near $22 \mathrm{C}$ resulted in the highest detection probability. Detection probability when surveying at the optimal temperature was approximately $6 \%$ and $7.5 \%$ greater than when surveying at $16 \mathrm{C}$ and $29 \mathrm{C}$, respectively (Fig. 2). Both WATER TEMPERATURE and WATER TEMPERATURE ${ }^{2}$ were statistically significant in the analysis $(\mathrm{P}<0.05)$, and the likelihood-ratio test was statistically significant $\left(\chi_{1}^{2}=27.34, \mathrm{P}<0.001\right)$, indicating that water temperature significantly impacted detection probability.

\section{DISCUSSION}

Our study indicated that WATER TEMPERATURE was an important environmental factor for detecting the endangered Diamond Darter. Presumably, WATER TEMPERATURE influenced the availability of fish to be detected rather than the probability of an observer detecting an individual that was available. There are a number of reasons why temperature may alter the behavior or micro-distribution of Diamond Darters, affecting their availability for sampling. One potential explanation involves the effect of temperature on metabolic rate. Fish activity, feeding, and other fundamental behaviors may vary with temperature changes that occur within a normal range of physiological tolerance (Stoner, 2004). Multiple studies have found that with most species of fish, food consumption normally increases steadily with temperature and then decreases rapidly - possibly because of limitations in the ability of the respiratory and circulatory systems to meet the high oxygen demand of respiring tissues (Brett, 1979; Jobling, 1997). While this potential explanation is plausible, we currently have no evidence that Diamond Darters are feeding during these night-time surveys, or whether this activity would be influenced by the temperature range we surveyed. Thus, additional research is necessary to determine causation. 
Another explanation that may explain why temperature is affecting detection probability may involve darters shifting their microhabitat use in an attempt to thermoregulate. In a study conducted by Ingersoll \& Claussen (1984), this behavior was noted in some species of darters living in stream/riverine systems; however, the shift in habitat use occurred between summer and winter months and not throughout the summer. In a laboratory study conducted by Ruble et al. (2014), Diamond Darters spent more time buried under the sand substrate at temperatures below $15 \mathrm{C}$, and were noted as being consistently above the substrate at water temperatures above $21 \mathrm{C}$. This lab study did not allow water temperature to exceed $25 \mathrm{C}$. Because of this, it is difficult to directly relate the results of their study with ours, although it does lend some support to temperature influencing Diamond Darter detection probability.

We found large variability in mean estimated abundance among the 3 study sites. Although the study was not designed to quantify predictors of abundance, one potential explanation is variation in microhabitat conditions at glide locations. Welsh et al. (2013) found that Diamond Darters appeared to be associated with substrate that was primarily composed of sand. Based on our results, it is likely that this association is due to higher abundances at sandier glide sites (i.e., Clendenin and Reamer). Future research should explicitly investigate factors (e.g., substrate type) that influence Diamond Darter occupancy and abundance.

The results of this study can be used to improve sampling efficiency and abundance estimation for Diamond Darters. We suggest that future surveys seek to sample during optimal water temperatures, as well as include measurements of water temperature for use as a detection covariate in abundance estimates. In addition, we found that HOURS AFTER SUNSET and DAY OF YEAR were not strong predictors of detection probability. Thus, timing of surveys is flexible within the ranges we studied, assuming WATER TEMPERATURE is appropriate. Future research is 
needed to determine the optimal number of survey replications for Diamond Darter abundance estimation. 
Acknowledgements.-The authors wish to thank NiSource and U.S. Fish and Wildlife Service for funding. We thank Joni Aldinger, Brian Crabill, Kevin Lambert, and Rich Raesly for field assistance. Any use of trade, firm, or product names is for descriptive purposes only and does not imply endorsement by the U.S. Government. This study was performed under the auspices of West Virginia University IACUC protocol 12-0205. 


\section{LITERATURE CITED}

Ali, M. A (ed.). 1992. Rhythms in fishes. Plenum Press, New York, New York, USA. 348 p.

Burnham, K. P. And D. R. Anderson. 2002. Model selection and multimodel inference: a practical information-theoretic approach. Springer-Verlag New York, Inc., New York, New York, USA. 488 p.

Bolker, B. M., M. E. Brooks, C. J. Clark, S. W. Geange, J. R. Poulsen, M. H. H. Stevens, and J. S. S. WHITE. 2009. Generalized linear mixed models: a practical guide for ecology and evolution. Trends Ecol. Evol., 24: 127-135.

BRETT, J. R. 1979. Environmental Factors and Growth, p. 599-675. In: W.S. HoAR, D. J.

RANDAll, and J. R. Brett (eds.). Fish Physiology. $8^{\text {th }}$ ed. Academic Press, Inc, New York, New York, USA.

Couturier, T., M. Cheylan, A. Bertolero, G. Astuc, and A. Besnard. 2013. Estimating abundance and population trends when detection is low and highly variable: A comparison of three methods for the Hermann's Tortoise. J. Wildlife Manage., 77: 464462.

DAIL, D., and L. MADSEN. 2011. Models for estimating abundance from repeated counts of an open metapopulation. Biometrics 67:577-587.

HARding, J. M., A. J. Burky, and C. M. WAY. 1998. Habitat preferences of the Rainbow Darter, Etheostoma caeruleum, with regard to microhabitat velocity shelters. Copeia, 4:988-997.

HLOHOWSKYJ, I., and T. E. WiSSING. 1985. Seasonal changes in the critical thermal maxima of fantail (Etheostoma flabellare), greenside (Etheostoma blennoides), and rainbow (Etheostoma caeruleum) darters. Can. J. Zoolog., 63:1629-1633. 
INGERSOLL, C. G., and D. L. Claussen. 1984. Temperature selection and critical thermal maxima of the fantail darter Etheostoma flabellare, and johnny darter, E. nigrum, related to habitat and season. Environ. Biol. Fish., 11: 131-138.

JoBLING, M. 1997. Temperature and growth: modulation of growth rate via temperature change. Soc. Exp. Biol. Sem. S., 61: 225-254.

Jones, R. N., D. J. ORTH, and O. E. MAUGHAN. 1984. Abundance and preferred habitat of the Leopard Darter, Percina pantherina, in Glover Creek, Oklahoma. Copeia, 1984: 374384.

JosePh, L. N., C. Elkin, T. G. Martin, and H. P. Possingham. 2009. Modeling abundance using $\mathrm{N}$-mixture models: the importance of considering ecological mechanisms. Ecol. Appl., 19: $631-642$.

KANNO, Y., B. H. LETCHER, J. C. VOKOUN, and E. F. ZIPKIN. 2014. Spatial variability in adult brook trout (Salvilinus fontinalis) survival within two intensively surveyed headwater stream networks. Can. J. Fish. Aquat. Sci., 71:1010-1019.

KENDALL, W. L. 1999. Robustness of closed capture-recapture methods to violations of the closure assumption. Ecology, 80:2517-2525.

KéRY, M. and J. A. RoyLE. 2016. Applied Hierarchical Modeling in Ecology: Analysis of distribution, abundance and species richness in R and BUGS, Volume 1. Academic Press/Elsevier Inc, San Diego, USA. 808 p.

MacKenzie, D. I., J. D. Nichols, G. B. Lachman, S. Droege, J. A. Royle, and C. A. LANGTIMM. 2002. Estimating site occupancy rates when detection probability are less than one. Ecology, 83: 2248-2255. 
MacKenzie, D. I., J. D. Nichols, J. A. Royle, K. H. Pollock, J. E. Hines, and L. L. Bailey. 2006. Occupancy Estimation and Modeling: Inferring Patterns and Dynamics of Species Occurrence. Elsevier, San Diego, California, USA. 324 p.

MacKenzie, D. I., J. A. Royle, J. A. Brown, and J.D. Nichols. 2004. Occupancy estimation and modeling for rare and elusive populations, p. 149-171. In: Thompson, W. L., (ed.). Sampling rare or elusive species; concepts, designs, and techniques for estimating population parameters. Island Press, Washington, DC., USA.

MAZEROLLE, M. J. 2016. Package 'AICcmodavg': model selection and multimodel inference based on (Q)AIC(c). R package version 2.0-4. <https://cran.rproject,org/web/packages/AICcmoda vg/>. Accessed 4 Apr 2016.

MCDonALD, L. L. 2004. Sampling rare populations, p. 11-42. In: Thompson, W. L., (ed.). Sampling rare or elusive species; concepts, designs, and techniques for estimating population parameters. Island Press, Washington, DC., USA.

MunDAHL, N. D. 1990. Heat death of fish in shrinking stream pools. Am. Midl. Nat. 123:40-46.

PitCHER, T. P., D. M. GUTHERIE, and W. R. A. MunTZ. 1993. Role of vision in fish behavior, p. 89-121. In: T. P. PITCHER (ed.). Behavior of Teleost Fishes. $2^{\text {nd }}$ ed. Chapman and Hall, London, United Kingdom.

ReEBS, S. G. 2002. Plasticity of diel and circadian activity rhythms in fishes. Rev. Fish. Biol. Fisher., 12:349-371.

Reeves, G. H., J. B. GrunBaum, and D. W. Lang. 2009. Seasonal variation in diel behavior and habitat use by age 1+ Steelhead (Oncorhynchus mykiss) in Coast and Cascade Range streams in Oregon, U.S.A. Environ. Biol. Fish., 87:101-111. 
Rizzo, A. A., S. A. Welsh, and P. A. ThOMPSON. 2017. A paired-laser photogrammetric method for in situ length measurements of benthic fishes. N. Am. J. Fish. Manage., 37:16-22.

ROYLE, J. A. 2004. N-mixture models for estimating population size from spatially replicated counts. Biometrics, 60: 108-115.

Ruble, C. L., P. L. RAKes, J. R. Shute, and S. A. Welsh. 2014. Captive propagation, reproductive biology, and early life history of the Diamond Darter (Crystallaria cincotta). Am. Midl. Nat., 172: 107-118.

Schaefer, J. F., E. Marsh-Matthews, D. E. Spooner, K. B. Gido, and W. J. Matthews. 2003. Effects of barriers and thermal refugia on local movements of threatened leopard darter, Percina pantherina. Environ. Biol. Fish., 66:391-400.

SMITH, R. K. and K. D. FAUSCH. 1997. Thermal tolerance and vegetation preference of Arkansas Darter and Johnny Darter from Colorado plains streams. T. Am. Fish. Soc., 126:676-686.

StONER, A. W. 2004. Review Paper: Effects of environmental variables on fish feeding: implications for the performance of baited fishing gear and stock assessment. J. Fish. Biol., 65: 1445-1471.

USFWS (U.S. FISH AND WILDLIFE SERVICE). 2013. Endangered and threatened wildlife and plants; endangered species status for the Diamond Darter. Federal Register, 78: 45074-45095.

Utne-PALM, A. C. 2002. Visual feeding of fish in a turbid environment: Physical and behavioral aspects. Mar. Freshw. Behav. Phy., 35: 111-128.

WelSH, S. A. and R. M. WoOD. 2008. Crystallaria cincotta, a new species of darter (Teleostei: Percidae) from the Elk River of the Ohio River drainage, West Virginia. Zootaxa, 1680:62-68. 
Welsh, S. A., R. M. WoOD, and K. R. SHEEHAN. 2009. Threatened fishes of the world: Crystallaria cincotta Welsh and Wood 2008 (Percidae). Environ. Biol. Fish., 84: 191192.

Welsh, S. A., D. M. Smith, and N. D. TAYlor. 2013. Microhabitat use of the Diamond Darter. Ecol. Freshw. Fish., 22:587-595.

Welsh, S. A., A. A. Rizzo, and P. A. Thompson. 2014. Distribution and abundance of the Diamond Darter in Elk River, West Virginia. Project report submitted to West Virginia Division of Natural Resources, Elkins, WV.

WENGER, S. J. and M. C. FreEMAN. 2008. Estimating species occurrence, abundance, and detection probability using zero-inflated distributions. Ecology, 89:2953-2959. 


\section{FIGURE CAPTIONS}

Figure 2. Map showing the three study sites (Walgrove, Reamer, and Clendenin Compressor Station) on the Elk River, West Virginia used to estimate abundance and factors affecting detection probability of the endangered Diamond Darter Crystallaria cincotta.

Figure 2. The relationship between water temperature and per-individual detection probability of the endangered Diamond Darter Crystallaria cincotta based on 45 surveys conducted at 3 sites in the Elk River, West Virginia. Bands show the 95\% confidence interval at each water temperature. 
Table 1. Ten candidate models for explaining variation in detection probability during surveys of the endangered Diamond Darter Crystallaria cincotta. For each model, the Akaike Information Criterion adjusted for sample size $\left(\mathrm{AIC}_{\mathrm{c}}\right)$, the delta $\mathrm{AICc}, \mathrm{AICc}$ weight $\left(w_{i}\right)$, the number of parameters $(\mathrm{K})$, and the maximum $\log$ likelihood $(-2 \log (L))$ are given. The variables evaluated include water temperature (WTEMP), turbidity, amount of light (SQM), gage height, hours after sunset, site, and day of year.

\begin{tabular}{ccccccc}
\hline \hline & Covariates & & & & & \\
Abundance & Detection & $\mathrm{K}$ & $\mathrm{AIC}_{\mathrm{c}}$ & $\Delta \mathrm{AIC}_{\mathrm{c}}$ & $w_{i}$ & $-2 \log (L)$ \\
\hline SITE & $\left(\right.$ WTEMP + WTEMP $\left.{ }^{2}\right)$ & 6 & 353.5 & 0.00 & 0.996 & -181.234 \\
SITE & $($ TURBIDITY X SQM $)$ & 7 & 365.0 & 11.54 & 0.003 & -186.703 \\
SITE & GAGE HEIGHT & 5 & 368.2 & 14.70 & 0.001 & -189.083 \\
SITE & TURBIDITY & 5 & 372.0 & 18.53 & 0.000 & -190.998 \\
SITE & SQM & 5 & 375.6 & 22.11 & 0.000 & -192.789 \\
SITE & $\sim$ & 4 & 377.8 & 24.34 & 0.000 & -194.904 \\
SITE & HOURS AFTER SUNSET & 5 & 378.1 & 24.60 & 0.000 & -194.034 \\
SITE & SITE & 5 & 378.7 & 25.28 & 0.000 & -193.874 \\
SITE & DAY OF YEAR & 5 & 379.8 & 26.34 & 0.000 & -194.904 \\
SITE & (DAY OF YEAR + DAY OF YEAR $\left.^{2}\right)$ & 6 & 380.8 & 27.34 & 0.000 & -194.904 \\
\hline
\end{tabular}




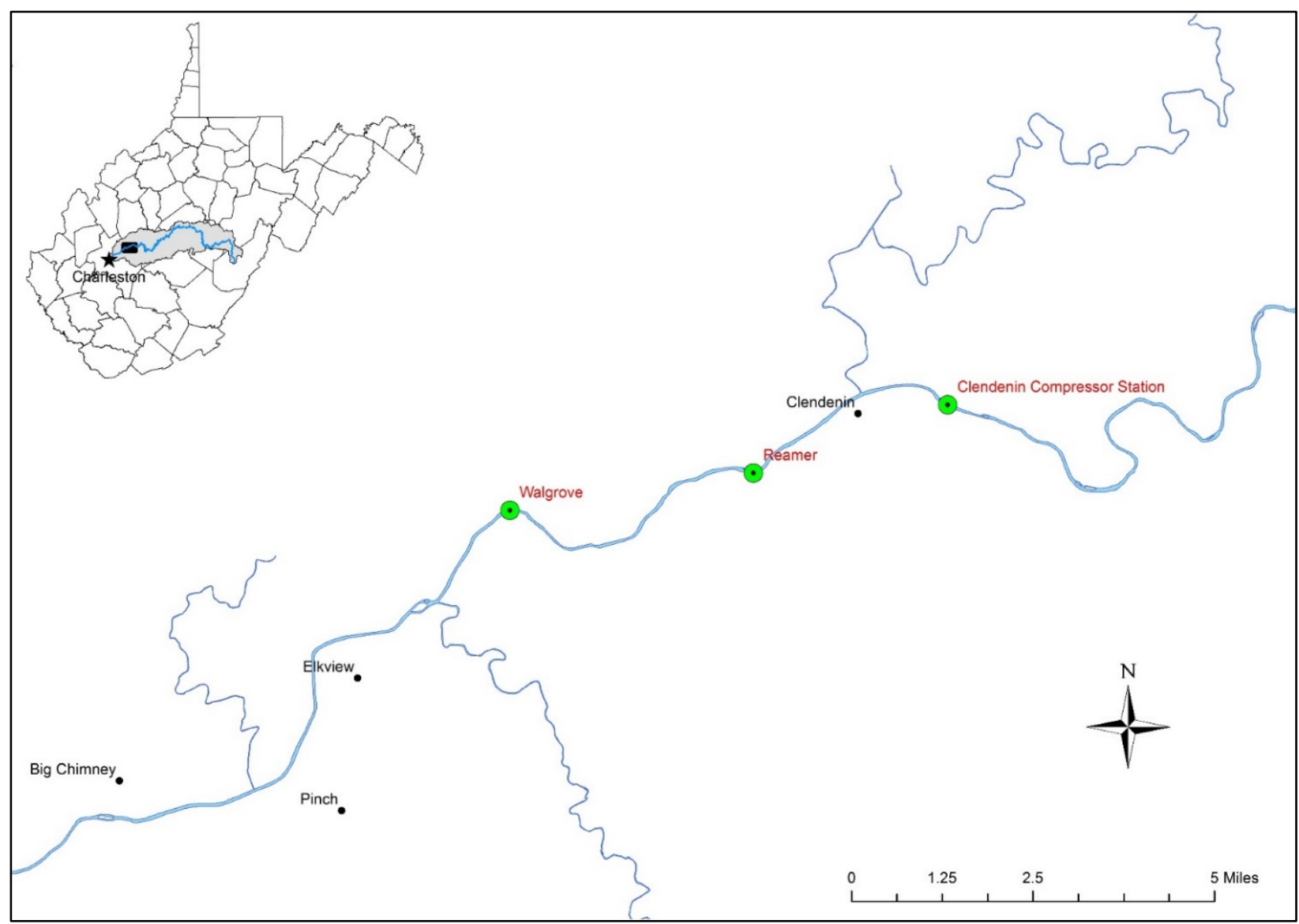

Figure 3. 


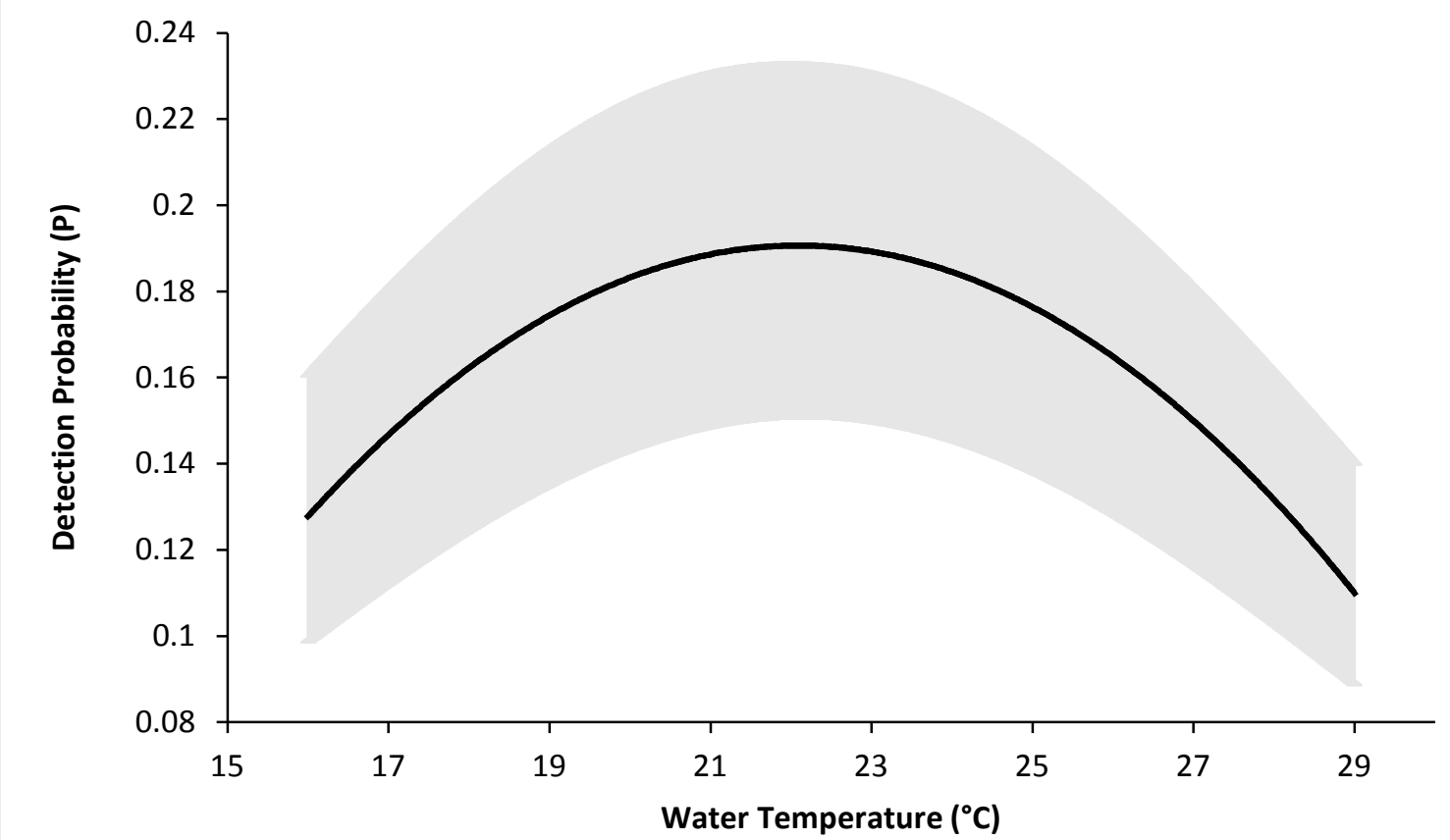

Figure 2. 
CHAPTER 3: Effects of an extreme flood event on federally endangered Diamond Darter populations: suggestions for survey and analysis design for future monitoring efforts

This chapter has been submitted to the journal Copeia and follows their required formatting.

Rizzo, A. A., D. J. Brown, C. T. Rota, S. A. Welsh, and P. A. Thompson. In review. Effects of an extreme flood event on federally endangered Diamond Darter populations: suggestions for survey and analysis design for future monitoring efforts. Copeia. 
Extreme flood events can substantially impact riverine systems, modifying in-stream habitat and influencing fish assemblages and densities. Rare species are especially vulnerable to these disturbance events because of their small population size and often reduced phenotypic heterogeneity. In June 2016, the lower Elk River in West Virginia experienced severe flooding, resulting in a peak discharge that exceeded the 0.005 annual exceedance probability $(>200$ year flood) in the main stem. Relative abundances for one cohort of the federally endangered Diamond Darter (Crystallaria cincotta) were estimated using pre-flood and post-flood surveys at 15 sites. Results indicate the short-term response of Diamond Darter relative abundances to this extreme event were negligible, indicating individuals are able to withstand high velocities and resist displacement or mortality. In addition, site-level abundances were estimated at three sentinel sites during 2015 and 2016 using a multinomial $N$-mixture model that accounted for variation in detectability resulting from water temperature. Mean estimated abundance varied among the three sites and between the two years. Our results suggest there is substantial variation in year-class strength between the two cohorts we sampled. Using detection probabilities generated from our highest supported model, we conducted simulation modeling to determine the number of replicate surveys needed to confidently estimate abundances at a site. Mean abundance estimates were similar with $\geq 7$ replications. It is recommended that survey efforts at established sentinel sites be continued on an annual basis in order to help determine factors influencing year-class strength. 
Disturbance events can significantly impact ecological systems, disrupting the physical environment and associated ecosystem, community, and population structure of organisms inhabiting these areas (Resh et al., 1988; Scheffer et al., 2001). The magnitude and frequency of disturbance events influences the structure of abiotic and biotic components of an ecosystem. In many ecosystems, the organisms present have evolved under the constraints imposed by the frequency and magnitude of disturbance events (Williams, 1998; Lytle and Poff, 2004). Climate change research predicts that disturbance events caused by weather extremes may increase in magnitude and frequency in some regions of the world (Aldous et al., 2011; IPCC, 2013). Research suggests that changes in the nature of disturbance regimes could push some ecosystems beyond a threshold of dynamic equilibrium (Scheffer et al., 2001; Jentsch et al., 2007; Death et al., 2015).

Extreme flood events (i.e., flows with a 1\% annual exceedance probability [AEP]) can greatly modify in-stream habitat (Death et al., 2015). The severity of such events on river geomorphology is largely contingent upon the nature of the stream channel form, magnitude of the flood, and the ability of floodwaters to become laterally expansive into floodplains and backwater areas (Lytle and Poff, 2004; Death et al., 2015). Major flood events can influence fish assemblages and fish densities, although the exact nature of the relationship between a flood and these features varies (Aldous et al., 2011). Research has shown that while some severe floods can negatively impact a lotic ecosystem, others have been found to have negligible effects, or even result in long-term benefits to an ecosystem (Williams, 1998; Death et al., 2015). A flood's impact on a fish population largely depends on the timing of the event relative to the ontogenetic stage of present cohorts, frequency and predictability of the event, magnitude and duration of the event, and the availability of refugia (Fausch et al., 2001; Lytle and Poff, 2004; Death et al., 
2015; George et al., 2015). Additionally, some research has suggested that aquatic systems already severely stressed by anthropogenic factors (e.g., high nutrient and contaminant loads, increased sedimentation, invasive species) may be more prone to being negatively affected by severe flood events (Staudt et al., 2013; Death et al., 2015).

Rare species are especially vulnerable to stochastic disturbance events because of their small population size and often reduced phenotypic heterogeneity (Caughley, 1994; Hellmair and Kinziger, 2014). Research has shown that rare species are at an elevated risk of extinction when disturbance events occur that are outside of the evolutionary experience of that species, especially when these disturbance events occur at a frequency that outpaces the adaptive capabilities of the species (Williams, 1998; Brook et al., 2008). For many species that have become extinct, the final quietus is often unrelated to those processes that initially triggered their population decline. Instead, the cause of extinction is often associated with stochastic events, such as genetic, demographic, catastrophic, and/or environmental events (Lande, 1993; Brook et al., 2008).

The Diamond Darter is a federally endangered fish that is only known to occur within the lower $50 \mathrm{rkm}$ of the Elk River in West Virginia. Museum specimens indicate the Diamond Darter was once distributed throughout the Ohio River Basin, but it is now likely extirpated from the Muskingum River, the Ohio River, the Green River, and the Cumberland River drainages (Welsh and Wood, 2008; Welsh et al., 2009; Welsh et al., 2014). The Diamond Darter is an extremely rare species and was placed on the Endangered Species List in 2013 because of its small range and population size, and because of continued anthropogenic threats to the species' habitat (USFWS, 2013). 
In this study, we investigated potential impacts of a high magnitude flood disturbance on relative abundance of Diamond Darters in the Elk River, West Virginia. Diamond Darter surveys were conducted at 15 sites within the lower $50 \mathrm{rkm}$ of the Elk River in 2016, as part of a study to evaluate distribution and population size of this species within the river. Approximately 1 week after our initial searches, the region experienced severe flooding from a series of thunderstorms that resulted in a rainfall recurrence interval of less than once every 1000 years in several areas of the Elk River watershed (Di Liberto, 2016). The peak flow at the Queen Shoals U.S. Geological Survey (USGS) stream gauge, immediately upstream of our study sites, was between 0.005 and 0.002 annual exceedance probability (AEP), which corresponded to a flood recurrence interval of 200 and 500 years, respectively (Wiley and Atkins, 2010). In addition, we assessed changes in mean estimated populations at three sentinel sites between the 2015 and 2016 sampling seasons. Finally, we conducted simulations to determine the number of survey replicates needed to confidently obtain mean population estimates. Collectively, these analyses provide useful insights into the potential short-term impacts of major flood events on the Diamond Darter, and provide valuable information that will be useful for future population monitoring efforts for this federally endangered fish.

\section{METHODS}

Study area.-The Elk River runs through the Appalachian Plateau in central West Virginia. The Elk follows a $290 \mathrm{rkm}$ course from its headwaters in Pocahontas County to where it meets the Kanawha River near the city of Charleston (Fig. 1). The 4,000 $\mathrm{km}^{2}$ watershed is $90 \%$ forested, with river geology largely consisting of sandstone and shale bedrock (Strager, 2008). The Elk is impounded at Sutton Dam (6 $\mathrm{km}^{2}$ reservoir) which is about $190 \mathrm{rkm}$ upstream of the mouth of 
the river. Below the dam, the river is characterized as being a low gradient river, with long deep pools separated by short riffle areas (Welsh et al., 2013). The Elk is currently on the state's Clean Water Act section 303(d) list because of impaired waters, due largely to violations of fecal coliform levels and dissolved metals (Strager, 2008). In addition, the Elk River has experienced a number of anthropogenic disturbance events in the last decade (Bahadur and Samuels, 2014; USCSB, 2016). While this river has experienced a number of different stressors, it is still regarded as being one of the most diverse rivers in West Virginia, with approximately 100 species of fish and 30 species of mussels. In addition, the Elk River has scored high on the West Virginia Stream Condition Index (WVSCI), which uses benthic macroinvertebrate metrics (WVDEP, 1997). Our study area includes the lower $50 \mathrm{rkm}$ of the Elk River where the Diamond Darter is known to occur (Fig. 1).

Data collection.-Sites were surveyed using a search method that employs the use of spotlighting at night with flashlights within wadeable sections of the river (Welsh et al., 2013). This method has proven to be effective in glide habitats (those areas of the river immediately upstream of riffles). These areas are shallow enough for a person to wade transects and they have a smooth water surface, which allows the spotlighter to see through the water column to the substrate (Welsh et al., 2013). As a result of water level fluctuations in the river, the number of transects required to search a site varied by sampling night. Consequently, there was no standard number of transects sampled per sampling occasion. Counts of Diamond Darters were summed across all transects at a site to get a total count during a sampling occasion (Rizzo et al., 2017a).

To investigate single-year pre-flood vs. post-flood relative abundance, 15 knownoccupied glide areas (sites) were sampled (Fig. 1). Sampling events included three searches 
conducted during 2016; one in mid-June (prior to the flood), one in July (after the water levels and turbidity had returned to pre-flood levels), and one in September (to determine if any lageffects of the flood occurred throughout the season). The 15 sites were originally intended to be included in a study assessing the influence of site-level habitat variables on local abundance.

To investigate multi-year changes in abundance, we used 3 of the 15 sites, which were each sampled 15 times between the months of May-October in 2015 and 2016. Periods of high river discharge or high water turbidity prevented sampling during the late fall and early spring, and periodically throughout the sampling season of both years. Only surveys conducted following the flood event were included in the analyses for the 2016 sampling season. This was done to ensure that the 2016 sampling season could be considered a 'closed-season' where no mass migration or mortality occurred - an assumption of the model (Donovan and Hines, 2007). In a previous study conducted in 2015 , water temperature was found to influence individual Diamond Darter detectability (Rizzo et al., 2017a). Thus, water temperature was recorded during each sampling event to use as a detection covariate.

\section{Data Analyses}

Pre-flood vs. post-flood relative abundance.-A paired randomization test with 10,000 iterations was used to determine if raw count numbers at each site differed between pre- and post-flood searches at the 15 sites. The $P$-value obtained from this test represents the proportion of trials resulting in a count difference between sampling events as great or greater than the one obtained (Sokal and Rohlf, 1995). This test was also performed using relative abundance data corrected 
for incomplete detection based on the relationship between water temperature and detection probability ( $p$; Rizzo et al., 2017a).

Multi-year changes in abundance. $-N$-mixture models were used to estimate site-level abundances at our three sentinel sites, using the software packages 'unmarked' (Fiske and Chandler, 2011) and 'AICcmodavg' (Mazerolle, 2016) in the program R (R Developmental Core Team, 2017). Water temperature was included as a $p$ covariate (Rizzo et al., 2017a). Model goodness-of-fit was evaluated using a parametric bootstrap of the Pearson chi-square statistic (Mazerolle, 2016). The goodness-of-fit test indicated the data were overdispersed, and we accounted for this by inflating the estimated standard errors and $95 \%$ confidence intervals (CI) based on the $\hat{c}$ value (i.e., 3.61; Kéry and Royle, 2016). A Poisson distribution was chosen for the state process after comparing Quasi-Akaike Information Criterion $\left(\mathrm{QAIC}_{\mathrm{c}}\right)$ values and residual diagnostic plots for three distributions (i.e., Poisson, zero-inflated Poisson, and negative binomial; Kéry and Royle, 2016).

To estimate abundances each year, we used single-season $N$-mixture models (Kéry and Royle, 2016). Because of our limited dataset, we chose to treat each site-year combination as a separate site, thus increasing our sample size for fitting abundance and detection covariate relationships. This 'stacked' site-year analysis, using a single-season model, has been shown to be a more effective method than a multi-season model when using $N$-mixture modeling on smaller datasets (Yamaura et al., 2011). By structuring the data like this, it essentially creates an open model in which abundance [site,year] is completely independent of abundance[site, year+1]. Demographic closure was assumed for each 'stacked' site based on analysis of population size structure throughout the season (Rizzo et al., 2017b). Additionally, adjusted 
population estimates were similar throughout the sampling season, lending support to our assumption that our populations were closed. Further, Kendall (1999) found that if individuals occupy and vacate a site in a random manner, estimators used to explain detection and abundance should remain unbiased.

A total of 4 a priori models were constructed based on our knowledge of Diamond Darter biology (Table 1). The number of models included was partially restricted by the small sample size. Model complexity was minimized in an effort to make interpretation simple, allowing researchers to identify those variables most responsible for variation in Diamond Darter abundances. Candidate models were ranked according to $\mathrm{QAIC}_{\mathrm{c}}$, corrected for small sample size. The model with the lowest $\mathrm{QAIC}_{\mathrm{c}}$ was considered to be the most parsimonious among the collection of candidate models, and all models within seven $\mathrm{QAIC}_{\mathrm{c}}$ values of the minimum were considered to have some support (Burnham and Anderson, 2002). A likelihood ratio test was used to verify that the best-fitting model was significantly more informative than the interceptonly model (Bolker et al., 2009). Abundances were estimated using the best-fitting model. A Wald test was then used to determine if detection and abundance variables of the best model were statistically significant $(\mathrm{P}<0.05)$.

Simulation models. - Simulation models were used to investigate the influence of number of replicate surveys on model accuracy. Using template code provided in Veech et al. (2016), we generated true abundance and hypothetical count data, and estimated abundance based on the count data using $N$-mixture models. To remove the potential influence of number of sites, we used $S=100$ sites for each of $J=3-10$ replicate surveys, and performed 1,000 simulation iterations. For each simulation iteration, we allowed mean abundance $(\psi)$ among sites to vary 
randomly from $8-48$ individuals, representing the $25^{\text {th }}$ and $75^{\text {th }}$ percentile values for estimated abundances among our study sites.

True site-level abundance $(N)$ was generated using random draws from a Poisson distribution based on $\psi$. At each site, $N$ was held constant over the $J$ survey occasions simulating a closed population. Hypothetical count data was generated for each survey replication based on $N$ and $p$, which was allowed to vary randomly from $0.15-0.25$ based on what we would expect when surveying during good and optimal water temperatures. For each simulation iteration, abundance at each site was estimated based on the hypothetical count data, and the proportional difference between mean estimated abundance and mean $N$ was calculated $(\widehat{N} / N)$. To gauge model performance based on number of survey replications, we calculated the median, minimum, maximum, and $25^{\text {th }}$ and $75^{\text {th }}$ percentile values from the 1,000 iterations.

\section{RESULTS}

Pre-flood vs. post-flood relative abundance.-We documented 36 Diamond Darters during preflood searches and 21 Diamond Darters during post-flood searches at our 15 study sites. Uncorrected relative abundances did not differ between pre-flood and post-flood searches $(\mathrm{P}=$ 0.296). Correcting relative abundances based on $p$ indicated total pre-flood abundance was 250 $(95 \% \mathrm{CI}=175.0-435.5)$, and total post-flood abundance was $190(95 \% \mathrm{CI}=131.4-339.9)$. Corrected relative abundances did not differ between pre-flood and post-flood searches $(\mathrm{P}=$ $0.673)$. 
Multi-year changes in abundance.-We detected Diamond Darters during 74 of the 90 total surveys in 2015 and 2016, resulting in a naive species detection probability of 0.82 . Counts at the three study sites ranged from 0-42 Diamond Darters detected during a single survey event in 2015, and 0-8 Diamond Darters detected during a single survey event in 2016. Predicted abundances between the 2015 and 2016 sampling seasons were significantly different $(\mathrm{P}<0.05)$, with the 2015 population estimate having a coefficient 1.6 times larger than the 2016 population estimate $(2015 \beta=4.26$, s.e. $=0.53 ; 2016 \beta=2.69$, s.e. $=0.64)$. Predicted abundances varied widely among the three sites, between both years. The Clendenin site had the highest abundance during both years $(2015 \hat{\lambda}=61.6[30.6-124.1] ; 2016 \hat{\lambda}=17.5$ [8.3-37.0]), followed by the Reamer site $(2015 \hat{\lambda}=51.0[25.1-103.7] ; 2016 \hat{\lambda}=14.5[6.8-30.8])$, and then the Walgrove site $(2015 \hat{\lambda}=$ $11.6[5.6-24.3] ; 2016 \hat{\lambda}=3.3[1.5-7.3])$. Estimated abundances at the Clendenin site and the Reamer site were not significantly different $(\mathrm{P}=0.237)$; however, both of these sites had significantly higher estimated abundances than the Walgrove site $(\mathrm{P}<0.05)$.

A model including site + year as abundance covariates was the only model with substantial support $\left(\mathrm{AIC}_{\mathrm{c}}=511.6, w_{i}=1.00\right.$; Table 1$)$. Water temperatures near $22 \mathrm{C}$ resulted in the highest detection probability. Detection probability when surveying at the optimal temperature was approximately $13.5 \%$ greater than when surveying at $14 \mathrm{C}$ and $30 \mathrm{C}$ (Fig. 2). The likelihood-ratio test was statistically significant $\left(\chi_{1}^{2}=116.64, \mathrm{P}<0.001\right)$, indicating that both site and year significantly influenced abundance estimates. 
Simulation models. - The proportional difference for $\widehat{N} / N$ based on simulations resulted in $25^{\text {th }}$ $75^{\text {th }}$ percentiles that ranged from $0.84-1.30$ with 3 surveys, to $0.92-1.12$ with 10 surveys (Fig. 3). The $25^{\text {th }}-75^{\text {th }}$ percentile range was similar when $\geq 7$ survey replications were completed.

\section{DISCUSSION}

Our study indicates short-term responses in Diamond Darter abundances to an extreme flood event in the Elk River, West Virginia were negligible. Previous research on this species suggests that only one cohort of Diamond Darters is being detected in glide habitat of the river (Rizzo et al., 2017b). Consequently, our analysis regarding the short-term effects of the flood on this species is restricted to this one cohort of individuals. Although our study is limited in scope, our data provide evidence that individuals are able to withstand high velocities and resist displacement or mortality. These results are consistent with other studies which have shown that many riverine fish species are well adapted to large flood events and are able to resist short-term direct impacts of these events (George et al., 2015; Carlson et al., 2016).

Although we did not find a significant impact of the flood event on abundance, we did find large variability in estimated abundances between the two years at our three sentinel sites. Because our analysis is restricted to a single cohort of individuals, our results suggest that there are substantial variations in year-class strength, at least between the age classes sampled during 2015 and 2016. There are a number of reasons why year-class strength of a population of fish might vary substantially among years, including both biotic and abiotic factors (Freeman et al., 1988; Cowx and Frear, 2004). High mortality, resulting from severe disturbance events that occur during vulnerable ontogenetic stages (e.g., egg, larval) of a species, can lead to low 
recruitment and subsequent poor year-class strength. While disturbance events can result in these fluctuations, many fish populations experience variation in year-class strength as a result of environmental factors unassociated with disturbance events (Cowx and Frear, 2004). Freeman et al. (1988) summarized a number of studies, demonstrating that among-year variability in the reproductive success of stream fishes can be influenced by the timing, duration, and magnitude of water level fluctuations. Koonce et al. (2011) reviewed a number of studies on members of the family Percidae, and concluded that water temperature was the dominant factor regulating yearclass strength. While natural processes can result in these fluctuations, anthropogenic disturbances, including effects of global climate change, can exacerbate conditions (Neuman et al., 1996; Casselman et al., 2002). Research conducted at larger spatial scales on a number of fish species indicates that synchrony in year-class strength tends to occur among populations (Cattaneo et al., 2003; Bunnell et al., 2010). Our data, although limited, were consistent with these findings, showing a synchronous decline in Diamond Darter abundances during the 2016 season. Variation in year-class strength in many species of fish is fairly common (Matthews, 1998). While this variation is generally inconsequential to the persistence of most taxa, species with short life spans may experience local population extirpations when there are successive years of poor year-class strength. For example, wide fluctuations in abundance of Etheostoma tippecanoe were attributed to the short lifespan of this species (Warren et al., 1986, Jenkins and Burkhead, 1994).

Consistent with Rizzo et al. (2017a), we found that water temperature was a strong predictor of detectability. This relationship is likely related to the effects of temperature on metabolic rate and subsequent feeding activity; ultimately influencing the availability of darters to be detected (Rizzo et al., 2017a). We are uncertain whether these fish are emerging from 
under the sandy glide substrate during ideal conditions or whether they are migrating into glide habitat from deeper adjacent pool habitat. Thus, additional research is necessary to determine where these fish seek refuge during less optimal conditions.

Our visual encounter survey design using the spotlighting technique, coupled with abundance estimation using $N$-mixture modeling, resulted in abundance estimates that appear to be reasonably accurate and precise for this rare species of darter. We found large variability in mean estimated abundance among the three study sites during both years. Although the study was not designed to quantify predictors of abundance, one potential explanation is variation in microhabitat conditions at glide locations. Welsh et al. (2013) found that Diamond Darters appeared to be associated with substrate that was primarily composed of sand, which is consistent with the higher abundances that we found at our sandier glide sites (i.e., Clendenin and Reamer). Future research is needed to explicitly investigate factors (e.g., substrate type, glide size, etc.) that influence Diamond Darter abundance.

Longevity of darters varies substantially depending upon the species and environmental conditions (Etnier and Starnes, 1993). While no information currently exists describing the longevity of the Diamond Darter, its sister species, the Crystal Darter Crystallaria asprella, has been shown to be relatively short-lived - averaging around 2-4 years in lifespan (Etnier and Starnes, 1993; George et al., 1996). Although the longevity of the Diamond Darter is unknown, it is likely similar to its sister species. For this presumed short-lived species, determining which variables influence year-class strength may help to provide valuable insight on life history characteristics of the Diamond Darter. To begin to accomplish this, we suggest continued monitoring efforts at these three sentinel sites on an annual basis because of high year-class strength variability. With respect to sampling design, we suggest that, at minimum, each site be 
surveyed 7 times annually in order to obtain reliable abundance estimates. Also, we suggest that replicate surveys be conducted when water temperatures are between $16 \mathrm{C}$ and $28 \mathrm{C}$, optimally near $22 \mathrm{C}$ to maximize $p$. Additionally, in order to satisfy the assumption of within-year demographic closure required by $\mathrm{N}$-mixture modeling, replicate surveys will need to take place between May and Oct. of the calendar year. Water temperature at each site, during each replicate survey, should be recorded for use as a $p$ covariate in abundance modeling. 


\section{ACKNOWLEDGMENTS}

The authors wish to thank NiSource and U.S. Fish and Wildlife Service for funding. We thank J. Aldinger, B. Crabill, K. Lambert, and R. Raesly for field assistance. Any use of trade, firm, or product names is for descriptive purposes only and does not imply endorsement by the U.S. Government. This study was performed under the auspices of West Virginia University IACUC protocol 12-0205. 


\section{LITERATURE CITED}

Aldous, A., J. Fitzsimons, B. Richter, and L. Bach. 2011. Droughts, floods and freshwater ecosystems: evaluating climate change impacts and developing adaptation strategies. Marine and Freshwater Research 62:223-231.

Bahadur, R. and W. B. Samuels. 2014. Modeling the fate and transport of a chemical spill in the Elk River, West Virginia. Journal of Environmental Engineering 141. http://dx.doi.org/10.1061/(ASCE)EE.1943-7870.0000930

Bolker, B. M., M. E. Brooks, C. J. Clark, S. W. Geange, J. R. Poulsen, M. H. H. Stevens, and J. S. S. White. 2009. Generalized linear mixed models: a practical guide for ecology and evolution. Trends in Ecology and Evolution 24:127-135.

Brook, B. W., N. S. Sodhi, and C. J. A. Bradshaw. 2008. Synergies among extinction drivers under global change. Trends in Ecology and Evolution 23:453-460.

\section{Bunnell, D. B., J. V. Adams, O. T. Gorman, C. P. Madenjian, S. C. Riley, E. F. Roseman,} and J. S. Schaeffer. 2010. Population synchrony of a native fish across three Laurentian Great Lakes: Evaluating the effects of dispersal and climate. Oecologia 162:641-651.

Burnham, K. P. and D. R. Anderson. 2002. Model selection and multimodel inference: a practical information-theoretic approach. Springer-Verlag New York, Inc., New York, New York, USA.

Carlson, A. K., M. J. Fincel, C. M. Longhenry, and B. S. Graeb. 2016. Effects of historic flooding on fishes and aquatic habitats in a Missouri River delta. Journal of Freshwater Ecology 31:271-288. 
Caughley, G. 1994. Directions in Conservation Biology. Journal of Animal Ecology 63:215244.

Casselman, J. M., D. M. Brown, J. A. Hoyle, T. H. Eckert. 2002. Effects of climate and global warming on year-class strength and relative abundance of smallmouth bass in eastern Lake Ontario. American Fisheries Society Symposium 31:73-90.

Cattaneo, F., B. Hugueny, and N. Lamouroux. 2003. Synchrony in brown trout, salmo trutta, population dynamics: a 'Moran effect' on early-life stages. Oikos 100:43-54.

Cowx, I. G. and P. A. Frear. 2004. Assessment of year class strength in freshwater recreational fish populations. Fisheries Management and Ecology 11:117-123.

Death, R. G., I. C. Fuller, and M. G. Macklin. 2015. Resetting the river template: the potential for climate-related extreme floods to transform river geomorphology and ecology. Freshwater Biology 60:2477-2496.

Di Liberto, T. NOAA. “'Thousand-year' downpour led to deadly West Virginia floods”. Climate.gov, 8 July 2016. Web. 15 Feb. 2017. https://www.climate.gov/newsfeatures/event-tracker/thousand-year-downpour-led-deadly-west-virginia-floods.

Donovan, T. M. and J. Hines. 2007. Exercises in occupancy modeling and estimation. http://www.uvm.edu/envnr/vtcfwru/spreadsheets/occupancy.htm

Etnier, D. A. and W.C. Starnes. 1993. The Fishes of Tennessee. The Univ. of Tennessee Press, Knoxville, TN.

Fiske, I. J. and R. B. Chandler. 2011. Unmarked: An R Package for fitting hierarchical models of wildlife occurrence and abundance. Journal of Statistical Software 43:1-23. 
Freeman, M. C., M. K. Crawford, J. C. Battett, D. E. Facey, M. G. Flood, J. Hill, D. J. Stouder, and G. D. Grossman. 1988. Fish assemblage stability in a southern Appalachian stream. Canadian Journal of Fisheries and Aquatic Sciences 45:1949-1958.

George, S. D., B. P. Baldigo, A. J. Smith, and G. R. Robinson. 2015. Effects of extreme floods on trout populations and fish communities in a Catskill Mountain river. Freshwater Biology 60:2511-2522.

George, S. G., W. T. Slack, and N. H. Douglas. 1996. Demography, habitat, reproduction, and sexual dimorphism of the Crystal Darter, Crystallaria asprella (Jordan), from southcentral Arkansas. Copeia 1996:68-78.

Hellmair, M. and A. P. Kinziger. 2014. Increased extinction potential of insular fish populations with reduced life history variation and low genetic diversity. PLOS ONE 9:e113139.

IPCC (Intergovernmental Panel on Climate Change). 2013. Climate change 2013: The Physical Science Basis. Contribution of Working Group I to the Fifth Assessment Report on Climate Change. Cambridge, UK: Cambridge University Press.

Jenkins, R. E. and N. M. Burkhead. 1994. Freshwater fishes of Virginia. American Fisheries Society. Bethesda, Maryland.

Jentsch, A., J. Kreyling, and C. Beierkuhnlein. 2007. A new generation of climate-change experiments: events, not trends. Frontiers in Ecology and the Environment 5:365-374.

Kendall, W. L. 1999. Robustness of closed capture-recapture methods to violations of the closure assumption. Ecology 80:2517-2525. 
Kéry, M. and J. A. Royle. 2016. Applied Hierarchical Modeling in Ecology: Analysis of distribution, abundance and species richness in R and BUGS, Volume 1. Academic Press/Elsevier Inc, San Diego, USA.

Lande, R. 1993. Risks of population extinction from demographic and environmental stochasticity and random catastrophes. The American Naturalists 142:911-927.

Lytle, D. A. and N. L. Poff. 2004. Adaptations to natural flow regimes. Trends in Ecology and Evolution 19:94-100.

Matthews, W. J. 1998. Patterns in freshwater fish ecology. Chapman and Hall, New York, NY.

Mazerolle, M. J. 2016. Package ‘AICcmodavg': model selection and multimodel inference based on (Q)AIC(c). R package version 2.0-4.

http://cran.r-project,org/web/packages/AICcmodavg

Neuman, E., E. Roseman, and H. Lehtonen. 1996. Determination of year-class strength in percid fishes. Annales Zoologici Fennici 33:315-319.

R Development Core Team. 2017. R: a language and environment for statistical computing. R Foundation for Statistical Computing, Vienna, Austria. ISBN 3-900051-07-0, URL http://www.R-project.org.

Rizzo, A. A., D. J. Brown, S. A. Welsh, and P. A. Thompson. 2017a. Factors influencing detection of the federally endangered Diamond Darter Crystallaria cincotta: Implications for long-term monitoring strategies. American Midland Naturalist. 16-051R2. 
Rizzo, A. A., S. A. Welsh, and P. A. Thompson. 2017b. A paired-laser photogrammetric method for in situ length measurements of benthic fishes. North American Journal of Fisheries Management 37:16-22.

Scheffer, M., S. Carpenter, J. A. Foley, C. Folke, and B. Walker. 2001. Catastrophic shifts in ecosystems. Nature 413:591-596.

Staudt, A., A. K. Leidner, J. Howard, K. A. Brauman, J. S. Dukes, L. J. Hansen, C.

Paukert, J. Sabo, and L. A. Solorzano. 2013. The added complications of climate change: understanding and managing biodiversity and ecosystems. Frontiers in Ecology and the Environment 11:494-501.

Strager, J. M. 2008. Diamond Darter (Crystallaria cincotta) status review - threats assessment data development. Final Report Prepared for: U.S. Fish and Wildlife Service, West Virginia Field Office, Elkins, WV.

USFWS (U.S. Fish and Wildlife Service). 2013. Endangered and threatened wildlife and plants; endangered species status for the Diamond Darter. Federal Register, 78:45074-45095.

USCSB (U.S. Chemical Safety and Hazard Investigation Board). 2016. Investigation Report: Chemical spill contaminates public water supply in Charleston, West Virginia. Report No. 2014-01-I-WV.

Veech, J. A., J. R. Ott, and J. R. Troy. 2016. Intrinsic heterogeneity in detection probability and its effect on $N$-mixture models. Methods in Ecology and Evolution 7:1019-1028. 
Warren, M. L., B. M. Burr, and B. R. Kuhajda. 1986. Aspects of the reproductive biology of Etheostoma tippecanoe with comments on egg-burying behavior. American Midland Naturalist 116:215-218.

Welsh, S. A. and R. M. Wood. 2008. Crystallaria cincotta, a new species of darter (Teleostei: Percidae) from the Elk River of the Ohio River drainage, West Virginia. Zootaxa 1680:62-68.

Welsh, S. A., R. M. Wood, and K. R. Sheehan. 2009. Threatened fishes of the world: Crystallaria cincotta Welsh and Wood 2008 (Percidae). Environmental Biology of Fishes 84:191-192.

Welsh, S. A., D. M. Smith, and N. D. Taylor. 2013. Microhabitat use of the Diamond Darter. Ecology of Freshwater Fish 22:587-595.

Wenger, S. J. and M. C. Freeman. 2008. Estimating species occurrence, abundance, and detection probability using zero-inflated distributions. Ecology 89:2953-2959.

Wiley, J.B., and J. T. Atkins Jr. 2010 Estimation of flood-frequency discharges for rural, unregulated streams in West Virginia: U.S. Geological Survey Scientific Investigations Report 2010-5033, 78 p.

Williams, M. J. 1998. Patterns in Freshwater Fish Ecology. Chapman \& Hall, New York, NY.

WVDEP (West Virginia Department of Environmental Protection). 1997. An ecological assessment of the Elk River Watershed, West Virginia. Charleston, WV. 
Yamaura, Y., J. A. Royle, K. Kuboi, T. Tada, S. Ikeno, and S. Makino. 2011. Modeling community dynamics based on species-level abundance models from detection/nondetection data. Journal of Applied Ecology 48:67-75. 


\section{FIGURE CAPTIONS}

Fig. 4. Map showing locations of 15 Diamond Darter Crystallaria cincotta study sites on the Elk River, West Virginia. The sites were used to investigate the potential influence of an extreme flood event on abundance (flood sites + sentinel sites), and between-year changes in abundance (sentinel sites). Sentinel site names (Clendenin, Reamer, and Walgrove) are included in the map.

Fig. 2. Relationship between water temperature and per-individual detection probability $(p)$ of the endangered Diamond Darter Crystallaria cincotta based on 90 surveys conducted at 3 sites in the Elk River, West Virginia during 2015 and 2016. The gray band encompasses the 95\% confidence interval.

Fig. 3. Proportional differences between mean estimated abundance of hypothetical count data using $N$-mixture models and mean true abundance $(\widehat{N} / N)$ of Diamond Darters based on a constant number sites $(\mathrm{S}=100)$ and a variable number of surveys $(\mathrm{J}=3-10)$. We allowed true mean abundance to vary randomly from 8-48 individuals, and generated true site-level abundances using random draws from a Poisson distribution based on the mean abundance. For generating hypothetical count data, we allowed individual detection probability $(p)$ during each survey replication to vary randomly from $0.15-0.25$, corresponding to probabilities associated with water temperatures from $16 \mathrm{C}-28 \mathrm{C}$. Circles show the median value, rectangles contain the 25-75th percentile of simulation replications, and lines contain the minimum and maximum values from 1,000 simulation replications. 
Table 1. Four candidate models for explaining variation in abundance of the endangered Diamond Darter Crystallaria cincotta based two survey years (YEAR) and three sites (SITE) in the Elk River, West Virginia. For each model, the Quasi-Akaike Information Criterion adjusted for sample size $(\mathrm{QAIC})$, the delta QAICc, QAICc weight $\left(w_{i}\right)$, the number of parameters $(\mathrm{K})$, and the maximum $\log$ likelihood $(-2 \log (L))$ are given. The null abundance model is represented as $\sim$. Each model included water temperature $\left(\right.$ WTEMP + WTEMP $\left.^{2}\right)$ as a detection probability $(p)$ covariate.

\section{Covariates}

\begin{tabular}{ccccccc} 
Abundance & Detection & $\mathrm{K}$ & $\mathrm{QAIC}_{\mathrm{c}}$ & $\Delta \mathrm{QAIC}_{\mathrm{c}}$ & $w_{i}$ & $-2 \log (L)$ \\
\hline SITE + YEAR & $\left(\mathrm{WTEMP}^{2} \mathrm{WTEMP}^{2}\right)$ & 7 & 511.6 & 0.00 & 1.00 & -276.778 \\
SITE & $\left(\right.$ WTEMP $\left.+\mathrm{WTEMP}^{2}\right)$ & 6 & 528.3 & 16.75 & 0.00 & -300.152 \\
$\sim$ & $\left(\right.$ WTEMP $\left.+\mathrm{WTEMP}^{2}\right)$ & 4 & 719.5 & 207.91 & 0.00 & -335.734 \\
YEAR & $\left(\right.$ WTEMP + WTEMP $\left.^{2}\right)$ & 5 & Inf & Inf & 0.00 & -310.020 \\
\hline
\end{tabular}




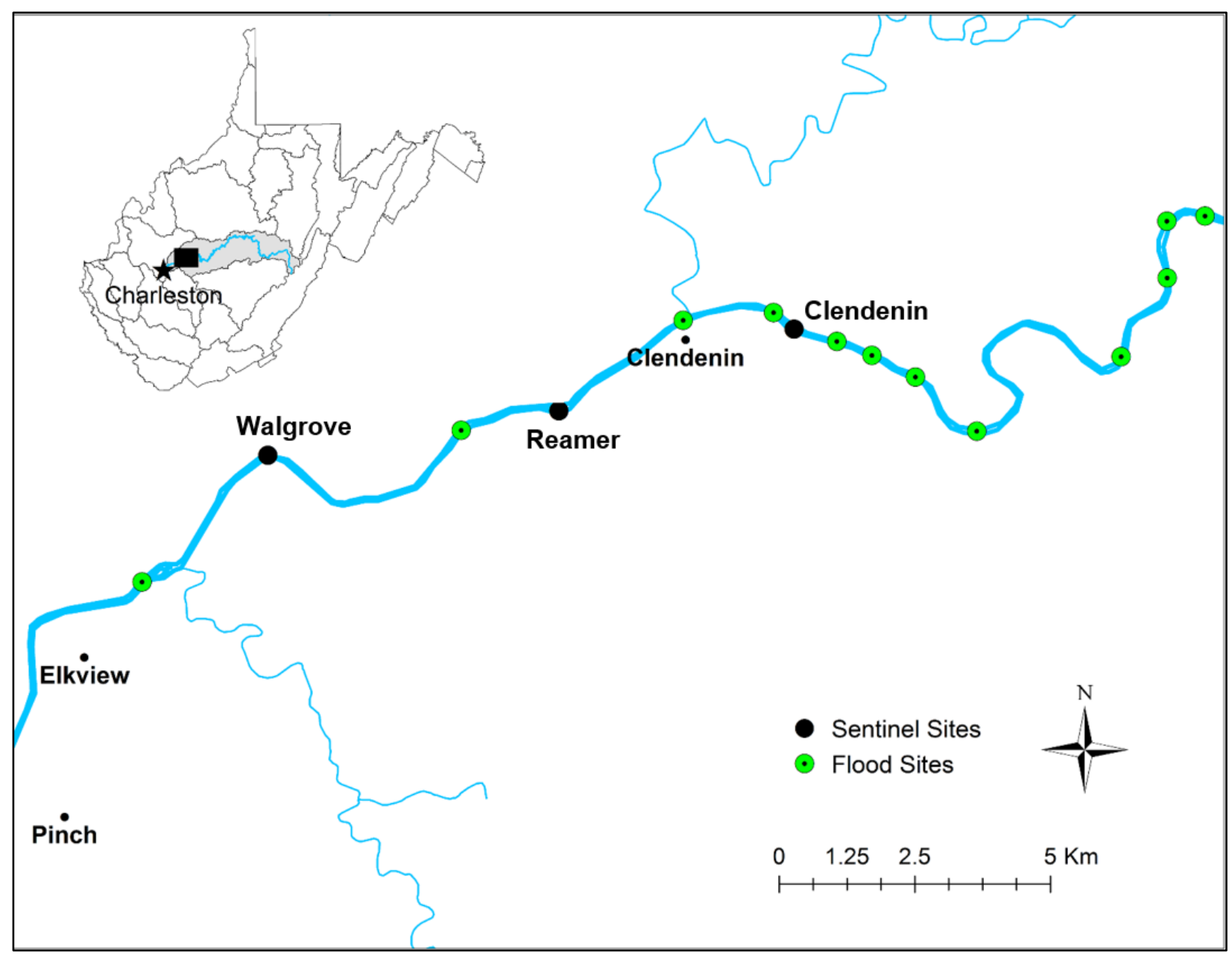

Fig. 5. 


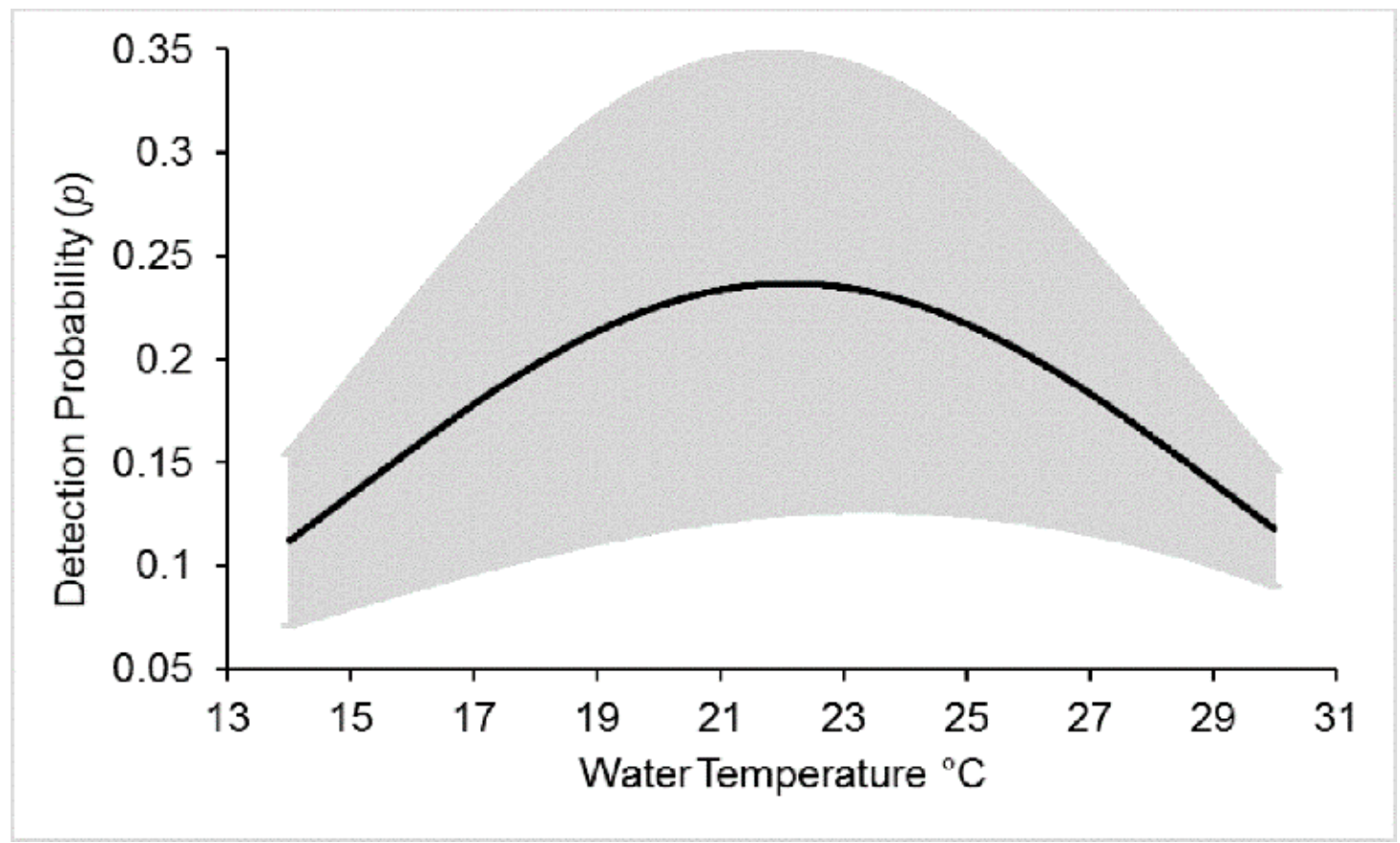

Fig. 2. 


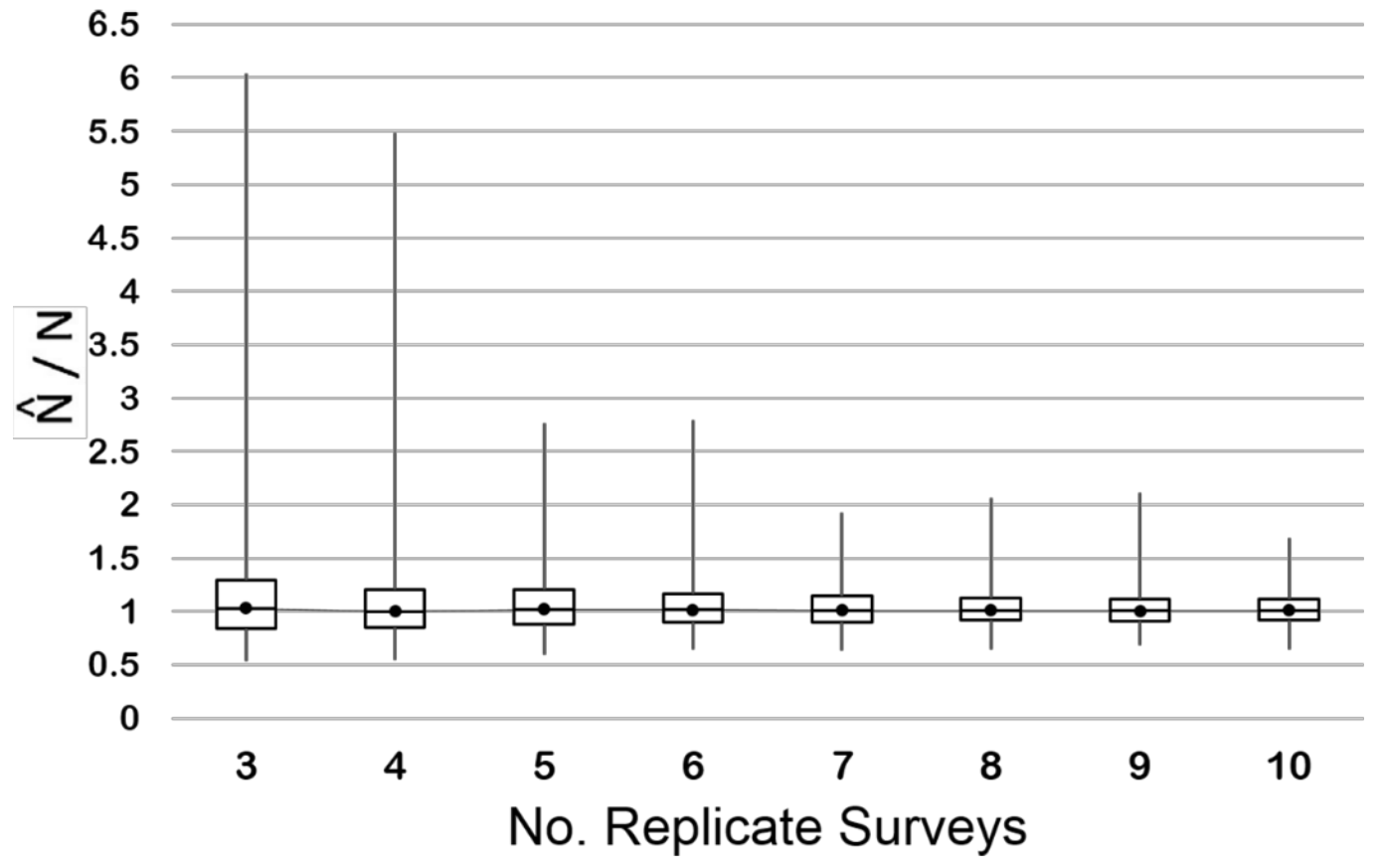

Fig. 3. 